\title{
Place-Based Campaigning: The Political Impact of Real Grassroots Mobilization
}

\author{
Daniel Bischof Aarhus University \& University of Zurich \\ Thomas Kurer University of Konstanz \& University of Zurich
}

September 21, 2022

\begin{abstract}
Generations of research have incrementally identified the circumstances under which electoral campaigns matter. Direct, interpersonal contact within local networks is commonly seen as conducive to campaign impact, but empirical evidence is scarce due to demanding data requirements. We advance the literature by studying the Movimento Cinque Stelle (M5S), an important challenger party in Italy, which followed the unusual practice of coordinating political activities on a public online platform. We web-scraped the entire history of the movement's more than 1,000 local branches with over 200,000 geocoded political activities to study the effect and mechanisms of their No-campaign in the 2016 constitutional referendum. Relying on regression, matching, and instrumental variable models, we demonstrate that local M5S mobilization had substantial campaign effects. Our results have important implications as they highlight the effectiveness of locally rooted campaigns and the particular potency of place-based political mobilization.

word count abstract $=149$;

full manuscript (excluding abstract) $=10,728$.
\end{abstract}

Correspondence: db @danbischof.com. We thank Tarik Abou-Chadi, Reto Bürgisser, Francesco Colombo, Elias Dinas, Sarah Engler, Florian Foos, Hanno Hilbig, Swen Hutter, Herbert Kitschelt, Hanspeter Kriesi, Arndt Leininger, Giorgio Malet, Tabea Palmtag, Nils Redeker, Tobias Rommel, Roman Senninger, Zeynep Somer-Topcu, Resul Umit, Kateřina Vráblíková, Vicente Valentim, Valerio Vignoli, Markus Wagner, and conference participants at EPSA 2019, APSA 2019, SVPW 2020, the Workshop on "Under pressure: Electoral and non-electoral participation in polarizing times", and during an invited talk at the University of Gothenburg for helpful comments. Ista Zahn provided valuable help during the web-scraping process. We thank Théoda Woeffray and Sebastian Weber for excellent research assistance (municipality-level data collection). We also thank Ruben Durante and Francesco Sobbrio for sharing their data on UGS stations in Italy. Thomas acknowledges support from a Berggruen-Weatherhead postdoctoral fellowship at Harvard University. Daniel acknowledges funding from the Swiss National Science Foundation (SNF Ambizione Grant, NO. 179938). Finally, we thank Alexandra Elbakyan. Replication files are available in the JOP Dataverse (https://dataverse.harvard.edu/dataverse/ jop). The empirical analysis has been successfully replicated by the JOP replication analyst. 


\section{Introduction}

Despite the increasing relevance of digital communication and social media in everyday politics, traditional on-the-ground mobilization remains at the heart of most political campaigns. Political activists who knock on doors, collect signatures at the local farmers market or approach pedestrians to promote their political purpose can be seen as the embodiment of political campaigning. The unabated reliance on local grassroots activism suggests that place-based campaigning is a continuously effective tool in the toolbox of modern political movements in general and for young challenger parties that lack resources and access to state funding in particular.

The effectiveness of political campaigning has attracted vast scholarly attention. Contrary to the "minimal effects" thesis that inspired early work, the more recent empirical evidence makes abundantly clear that campaigns do matter in a variety of important ways (Jacobson 2015). Rather than questioning whether campaigning pays off, a sophisticated experimental literature has moved on to illuminate the context conditions that amplify the effectiveness of a given campaign, such as different mobilization tactics, messages or targeting strategies (see Green and Gerber 2019).

Interestingly, the role of local, place-based campaigning - e.g. the political relevance of the grassroots activist at the farmers market - has received relatively little empirical attention. Although few people would question the importance of grassroot campaigns in terms of political mobilization, especially for emerging parties, existing empirical work tends to focus on professional campaigns organized top-down and under a common strategy, slogan and perhaps even canvassing script. This focus on elite-based campaigning conflicts with evidence questioning the efficacy of professional canvassing that lacks the interpersonal component of truly local campaigning (Enos and Hersh 2015; Sinclair, McConnell, and Michelson 2013). However, systematic empirical evaluations of real grassroot mobilization are hampered by the evident difficulty of comprehensively capturing the existence, intensity and type of such place-based campaigns. Related work on 'constituency campaigns' has thus resorted to indirect measures relying on spatially concentrated campaign spending estimates or self-reported information on partisan activity and canvassing exposure (e.g. Huckfeldt and Sprague 1992; Whiteley and Seyd 1994; André and Depauw 2016; but see Ellinas and Lamprianou 2019).

We address this research gap by turning to the Movimento Cinque Stelle (M5S), perhaps the most electorally successful populist party in Europe in the past decade (Mosca and Tronconi 2019). Not 
unlike other comparable political actors in (Southern) Europe, the M5S emerged in a political context of increasing political discontent with mainstream parties whose structural roots have been amplified by the harsh economic conditions and austerity policies in the aftermath of the Great Recession (Kriesi 2014; Font, Graziano, and Tsakatika 2021). Due to its self-conception as a bottom-up movement, the M5S has long coordinated all political activities on a public online platform. This feature of its organizational structure allows for uniquely transparent insights into the local campaign intensity of a modern political movement. We were able to collect the entire universe of decentralized M5S activity from the first day of its existence, resulting in a geocoded collection of more than 200,000 events organized by more than 1,000 independent local chapters with an average of 134 members in 896 locations in Italy. We map individual locations into political entities to create a novel data set that provides daily information on M5S activity in each of Italy's 8,000 municipalities between July 2005 and December 2018. Our data is equivalent to a complete and locally disaggregated event history of M5S activity and thereby helps overcome a key obstacle to studying the effects of local campaigns.

We then focus on a central political battle in the recent history of the movement, namely its role in the rejection of a constitutional reform in the 2016 referendum, which led to the resignation of then Prime Minister Matteo Renzi. While M5S was not the only party campaigning for a No vote, it was certainly the loudest advocate. We combine our rich event data with actual referendum results on the municipality level as well as individual-level panel data. Using regression, matching and instrumental variable models along with placebo tests, we find consistent evidence that events organized by local activists had a systematic and non-negligible effect on the referendum result. Robust within-individual evidence suggests that the primary channel through which the campaign increased opposition to the reform is persuasion rather than activation of undecided citizens.

At first sight, the robust finding that M5S campaigning significantly shifted the political outcome contrasts with the idea that campaign contact is unlikely to influence voters' choices (Kalla and Broockman 2018). A first reason could be our focus on a referendum whose result might be more malleable than that of an election campaign due to more ambiguous political cues (LeDuc 2003; de Vreese 2007). In addition, building on the literature that emphasizes the importance of social networks for attitude formation in general (Sinclair 2012) and campaigning in particular (Sinclair, 
McConnell, and Michelson 2013; Handan-Nader et al. 2021), our findings suggest that naturally occurring grassroots campaigns rooted in the local political environment could be more effective than the more artificial interventions of professional canvassing (for discussion, see, e.g., Green and Gerber 2016).

Importantly, our unique data set enables us to carefully investigate a pivotal observable implication of such an interpretation. Taking advantage of the fine-grained spatial disaggregation of our data, we show that the impact of place-based campaigning is indeed hyper-local: M5S activity only affects local referendum outcomes, and we do not find any spillover effects on the referendum result in neighboring municipalities. The absence of spatial spillovers corroborates previous evidence that social networks and peer pressure rather than pure informational cues make a political campaign effective (Sinclair, McConnell, and Michelson 2013). Our article thus highlights the particular potency of place-based grassroots mobilization in a rigorous empirical set-up.

As a final step, we have a closer look at the contextual conditions of the direct effect of $\mathrm{M}_{5} \mathrm{~S}$ mobilization on the referendum outcome to shed light on underlying mechanisms. This contextualization further adds to a more refined understanding of how exactly local campaigns affect political outcomes. First, individual event descriptions allow for a differentiation of indoor and outdoor activities. We find that only the latter have a measurable impact on the referendum outcome, implying that politicization of bystanders is a more powerful mobilization channel than private networks of highly involved activists. Second, we show that despite the movement's reliance on the internet to coordinate events, much of the actual politicization happens in real-world encounters and discussions. Third, we demonstrate that M5S activities primarily reach like-minded citizens. Persuasion of voters with divergent political preferences or mobilization of non-active citizens do not appear as similarly relevant sources of influence.

In sum, we provide evidence of spatially highly concentrated, personal and direct mobilization effects of place-based campaigning, which highlights the lasting importance and particular effectiveness of local political activism and traditional partisan bottom-up mobilization in an age of ubiquitous digital communication. 


\section{Parties, Activists and Local Campaigning}

Research on party organization suggests that activists play an important role for political parties' electoral success and survival (Panebianco 1988; Mair 2009). On the one hand, party activists - the facilitators of local campaign activities - are understood to provide a major impetus to party elites, especially in terms of a party's programmatic development (e.g. Kitschelt 1994; Schumacher, de Vries, and Vis 2013). On the other hand, local activists provide important support on the ground, be it by activating voters via their personal networks, organizing party gatherings or performing traditional campaign tasks (Kitschelt 1994; Whiteley and Seyd 1994; André and Depauw 2016). However, existing empirical research hardly ever fully integrated the influence of grassroots activities but resorted to indirect measures such as expert interviews, campaign spending data or self-reported partisan activity. The main reason for this neglect is a crucial measurement issue: to date it has been difficult - if not impossible - to capture activities undertaken by any party's grassroots organization in an encompassing way.

Instead, we have to turn to the classic campaign literature to arrive at a better understanding of how local political activism might contribute to a party's success. Departing from the long dominant minimal effects hypothesis (Lazarsfeld, Berelson, and Gaudet 1948), generations of research have demonstrated that campaigns matter in various important ways (Jacobson 2015). Recent research converges on the view that campaign events tend to have small (Pons 2018) or even no persuasive effects (Kalla and Broockman 2018).

While this very rich literature provides important insights about how professional campaigns may affect political outcomes, it rarely engages with the full scope of partisan activity as conceptualized and theorized in the constituency campaigning literature. Instead, the focus is on experimental manipulation on a smaller scale, which provides highly relevant insights into the causal relationship between campaigns and political outcomes under close control. But as Pons (2018: 1324) outlines, control is much more limited in large-scale campaigns where well-known principal-agent problems (Enos and Hersh 2015) may reduce the impact of the campaign. More importantly, experimental research - even when randomizing canvassers (Gerber and Green 2000; Foos and John 2018) - rarely studies decentralized bottom-up mobilization by local activists on the ground. The nature of such decentralized campaigning is much less coordinated, more spontaneous and personal, includes 
more diverse messages and likely centers around local political conflicts. Large-scale canvassing campaigns have a distinct top-down flavor, even if the actual door-to-door exercise is performed by volunteer activists. Such systematic canvassing endeavors tend to neglect idiosyncratic and often highly local political grievances that underpin typical grassroots mobilization. Indeed, individuals who are typically willing to volunteer in professional canvassing campaigns may be relatively ineffective because of their demographic and ideological differences from local voters and misconceptions of local political priorities (Enos and Hersh 2015).

Although social networks, interpersonal contact and peer pressure are well known determinants of individual political behavior (e.g. Huckfeldt 1979; Putnam 2000; Sinclair 2012; Doherty et al. 2017), these aspects rarely feature in professional, often somewhat artificial campaigning and canvassing carried out by paid workers or volunteers (for more in-depth discussion, see Green and Gerber 2016: 742). This is an important omission. Sinclair (2012) has powerfully argued and demonstrated that social networks do not primarily change political attitudes because they provide members with new information but because they activate a sense of norm conformity among peers. This clarification of the mechanisms behind politically relevant network effects implies that the social and local context of a campaign should be a key determinant of its effectiveness: campaign messengers might be a more powerful factor than the message itself.

There are apparent reasons for the relative neglect of the local context in existing work. ${ }^{1}$ First, the dominant experimental approach to studying campaign effects draws its strength and validity from randomizing exactly this match between messenger and recipient, i.e. between canvasser and potential voter. Messenger effects are hence not of primary interest in this setting. However, two notable exceptions demonstrate that close geographic proximity between voter and volunteer matters: door-to-door visits from canvassers who can be perceived as 'neighbors' are more effective than visits by canvassers from other neighborhoods or districts (Sinclair, McConnell, and Michelson 2013; Handan-Nader et al. 2021). This finding thus supports the conjecture that the mere informational aspect of a campaign message is less important than the social context of the interaction and, perhaps, the credibility of the messenger.

\footnotetext{
1To be sure, while there is agreement that 'the "who" rather than the "what"' of a campaign has been much less investigated (Handan-Nader et al. 2021: 146), existing studies have looked at other aspects of the messenger in examining the role of social influence on turnout and political behavior, e.g. the impact of the household (Nickerson 2008), intimate networks (Foos and De Rooij 2017) or co-ethnicity (Barreto and Nuño 2011).
} 
For understandable reasons, the attention to social network effects in non-experimental campaign studies is even less pronounced. Systematically studying variation in the local context of a campaign is very challenging in terms of data availability and poses obvious empirical obstacles, which force researchers to resort to the above-mentioned indirect measures. ${ }^{2}$ Thus, we identify a considerable need to examine whether and how decentralized, place-based grassroots mobilization, i.e. the epitome of political campaigning, helps political actors gain ground in political contestation. By studying the effect of truly local M5S campaigning during the 2016 constitutional referendum, we seek to provide relevant evidence regarding this research question.

\section{The Case: M5S, MeetUp and Italy's 2016 Constitutional Referendum}

In contrast to its current position as a major player in Italian politics, M5S started out as a scattered anti-corruption and anti-establishment movement (e.g. Bordignon and Ceccarini 2013). At the movement's infancy, communication between its charismatic founder Beppe Grillo and his sympathizers was heavily concentrated on Grillo's personal blog. As interest in the movement grew, Grillo felt overwhelmed by the volume of traffic on his blog and suggested that his followers organize independently on MeetUp (Grillo 2005), a public online platform for hosting in-person events. MeetUp groups rapidly became a major organizational resource, which squared nicely with the movement's conception of politics as bottom-up democracy (Bordignon and Ceccarini 2013). While MeetUp served as an organizational tool, actual events took place in public spaces, restaurants or private homes. The use of this specific platform is thus by no means an idiosyncracy of the case at hand but can be seen as a functional equivalent to other popular and publicly accessible online tools to mobilize supporters, including Facebook groups, Telegram chats or specific platforms that aim at facilitating political organization (e.g. ActionNow).

The M5S had and still has a complicated relationship to political power, raising the question how to best gauge the effectiveness of the movement's campaigning in the electoral sphere. For long, the movement outright rejected participation in elections due to its denouncing of rampant corruption and strong dislike for the political elite (Kriesi 2014). Election results thus provide a noisy and possibly misleading indicator of the movement's mobilization capacity. However, much in contrast to the

\footnotetext{
${ }^{2} \mathrm{~A}$ notable exception is a recent study on the electoral impact of party activities of the Golden Dawn, a Greek far-right party, which draws on an inventory of self-reported activities by local party branches (Ellinas and Lamprianou 2019).
} 
ambiguous position towards representative democracy, the M5S has shown strong and unambiguous support for more direct means of democratic participation in general and referendums in particular. We hence focus on direct-democratic political contestation rather than on election campaigns.

More specifically, we study the outcome of the 2016 constitutional referendum, a key political battle in the recent M5S history. Then Prime Minister Renzi (Partito Democratico) proposed a major political reform that sought to amend 47 articles of the Italian Constitution in an attempt to redesign the institutional architecture of the Republic. Importantly, Renzi personalized the vote from the very start of the referendum campaign by equating a 'yes' to the reform with support for his premiership (Ceccarini and Bordignon 2017: 289). This personalization created a strong opposition versus government dynamic. Indeed, much of the parliamentary opposition mobilized against the reform with M5S as the most vocal opponent. The referendum was held on 4 December 2016 and brought Renzi a spectacular defeat, leading to his resignation as prime minister. Supporters of the M5S showed the highest party discipline and cohesion with almost unanimous rejection of the reform (Pasquino and Valbruzzi 2017).

In general, referendums have become a much more common feature of Western democracies in recent decades, especially with respect to ratifying international agreements, and outcomes increasingly go against the governments' preferences (De Vries, Hobolt, and Walter 2021). Interestingly, despite the increasing prominence of national referendums, campaigning in that context has received little attention. The few existing studies suggest that political campaigning may be just as - if not more - important in determining outcomes in referendums as in elections (LeDuc 2003). This is because informational cues from parties and political actors tend to be much more ambiguous in referendums than in elections. A possible consequence is significant swings in pubic opinion, which highlights the relevance and potential influence of political campaigns (de Vreese 2007).

Our analysis aims to contribute to closing this important research gap. To illustrate how M5S organized its activities via MeetUp during the 2016 constitutional referendum, we focus on a MeetUp group in Pontinia, a small municipality in the province of Rome. The local chapter ("Grilli in Movimento per Pontinia") was founded in 2012, has organized 193 public events since then, and currently has 115 members. The group was born as a "meeting point for all those who join or sympathize with the 5 Star Movement in the area of Pontinia", and its self-description highlights ideological independence 
("neither left nor right, but ideas") and the desire for "democratic confrontation outside of association and partisan ties". A typical event during the campaign before the 2016 referendum would take place outdoors on a Saturday morning at the Piazza Indipendenza with the aim to "spread the reasons for the NO to the constitutional referendum on December 4. Take part with us in the infopoint banquets, you know the reasons for the NO. Activist help us spread the leaflets [...]". Beyond the organizer, who according to his MeetUp profile has never been a member of a party but always "followed politics as a critical observer", the event had five confirmed attendees from among the group's active members. ${ }^{3}$

\section{How Local M5S Activism Affects the Referendum Outcome}

As the example above outlines, local M5S chapters operate fully independently, organize events according to their liking and set the political agenda of these events - a key difference to top-down campaign efforts. These local campaign activities spread across the entire spectrum of political mobilization: from small-scale meetings in private homes to meetings that allow participants to engage with active M5S representatives in public buildings like the local library, up to large-scale mobilization events to share campaign materials in public spaces. Thus, the full scale of M5S activity against the reform goes well beyond the typical campaign tools analyzed in the campaign literature and is multifaceted - even within a given municipality.

Even though the traditional "minimal effects" thesis that initially inspired much research on campaigning has not survived recent generations of empirical research (Jacobson 2015), one might still question the ability of scattered, uncoordinated M5S branches to sway the outcome of a national referendum. Even more so in light of efforts on the national level via traditional and social media. However, we argue that the compartmentalized nature of such local groups is the distinguishing feature of the political power of decentralized challenger parties.

Political groups entrenched in villages or neighborhoods are easily accessible for ordinary citizens and provide an ideal context to understand, voice and mobilize local interests and grievances. Tightknit social networks and continuing deliberation and debate result in perhaps small but powerful organizations. The national movement learns about localities and their problems through bottom-up engagement with local interests and is dedicated to providing a meaningful platform that channels

\footnotetext{
${ }^{3}$ Quotes were translated from Italian. For original formulations and full information on the quoted examples, see group link and event link, respectively.
} 
local grievances into a generally applicable political punchline.

While most M5S MeetUp groups are characterized by specific debates and varying issue emphasis related to the local political context, a unifying topic is a strong dislike for the political elite (Kriesi 2014). Hence, a strongly personalized national referendum that would decide the future of the prime minister, i.e. the most visible symbol of the central government, certainly provides a gratifying target for the M5S. A first key expectation is that the presence of a local chapter and the intensity of its political mobilization increases votes against the reform.

We are equally interested in the underlying mechanisms of the effect of M5S activity - what ties grassroots mobilization to changes in political outcomes? First, we ask how local grassroots mobilization affects electoral results by focusing on the extent to which local M5S mobilization activities transcend municipal boundaries. On the one hand, the fact that M5S chapters are strongly rooted in local communities might suggest that their activities primarily resonate within their local electoral sphere. On the other hand, given that modern campaign tools heavily rely on digital communication and social media, it is not unreasonable to assume processes of diffusion. In our case, this would mean that a local chapter might affect referendum outcomes not only in the same municipality but also in close-by communities by word-of-mouth and regional mobility of interested citizens. While spillover effects of campaigns have been studied within tight social networks (e.g. Nickerson 2008; Foos and De Rooij 2017), we are not aware of studies that look at arguably even more consequential regional spillovers.

Second, we ask who is mobilized by M5S activities in order to arrive at a more nuanced interpretation of our direct effect. For one, we have detailed information on the place and type of all gatherings in our data set, which provides an invaluable source of insight with respect to the kind of audience that is reached by a specific event. This variation allows us to shed light on the relative effectiveness of social network effects resulting from small-group discussions at private homes as opposed to bystander effects of public events like leaflet distribution at the local piazza. In addition, we examine whether the effectiveness of the M5S campaign varies with partisan attachment. Drawing on insights from the traditional campaign literature in the context of elections, it is likely that the movement's campaign against the constitutional reform was particularly popular among citizens who feel close to the party and have supported them in previous elections. The part of our empirical analysis that 
builds on individual-level panel data allows for a straightforward examination of this longstanding and important debate (see, e.g., Lazarsfeld, Berelson, and Gaudet 1948; Kalla and Broockman 2018) in the context of the 2016 referendum.

\section{Data}

To test whether and how M5S' grassroots activities affected the outcome of the 2016 referendum, we collected complete data on all activities organized by the more than 1,000 local M5S chapters across the country. We then combined these geocoded event data with the actual referendum results for all 7,998 Italian municipalities as well as with a detailed individual panel study on the 2016 referendum.

\subsection{The M5S MeetUp data}

To retrieve full information about all events organized by M5S, we web-scraped the complete set of events organized by each group identified as relevant. We followed a multi-step procedure to obtain the universe of relevant groups (see Appendix A.1 for details), resulting in a cumulative total of $N=1,044$ local M5S chapters across the country (as of December 3,2018 ).

For each group, we first retrieved full group-level meta data. ${ }^{4}$ and then scraped its full event history. This yielded $N=217,218$ events between 2005 and 2018 organized by all 1,044 groups.

For each event, we have the following information: event ID, event description, event title, event creation date, event date/time, RSVP count, waitlist count, event URL. For about one third of the events, we even have the precise venue, e.g. "Piazza Bellini" or "Osteria della Fontana" (venue ID, venue name, venue latitude, venue longitude, venue address, venue city, venue state, venue ZIP, venue country). In cases where no precise venue is given, we impute event location with the precise location of the group, which is always known.

To give a first impression of the sheer amount of activities conducted by each M5S group, Figure 1 shows the cumulative number of unique groups on the left-hand side and the corresponding monthly number of events on the right-hand side. Immediately after Grillo's call to organize on MeetUp, the first groups started to emerge. ${ }^{5}$ The spread of local groups continued gradually, with a marked

\footnotetext{
${ }^{4}$ The meta data contain: group URL, group ID, group creation date, group name, group location, group latitude, group longitude, group state, group country.

${ }^{5}$ One chapter in Milan had used MeetUp before and might have served as inspiration.
} 
(a) Cumulative Number of Groups

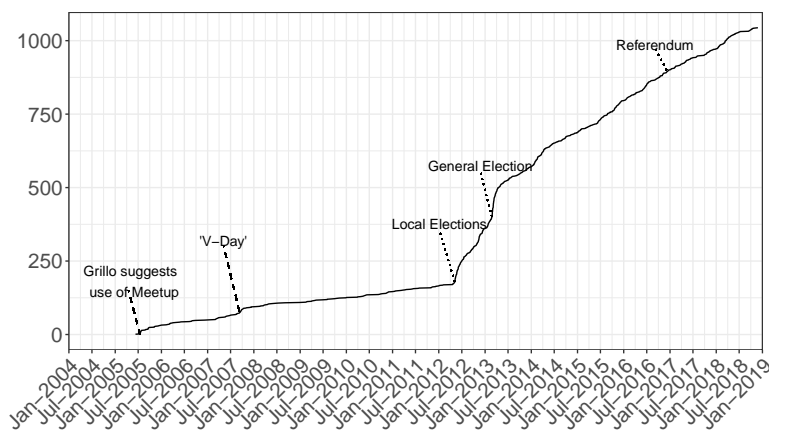

(b) Monthly Number of Events

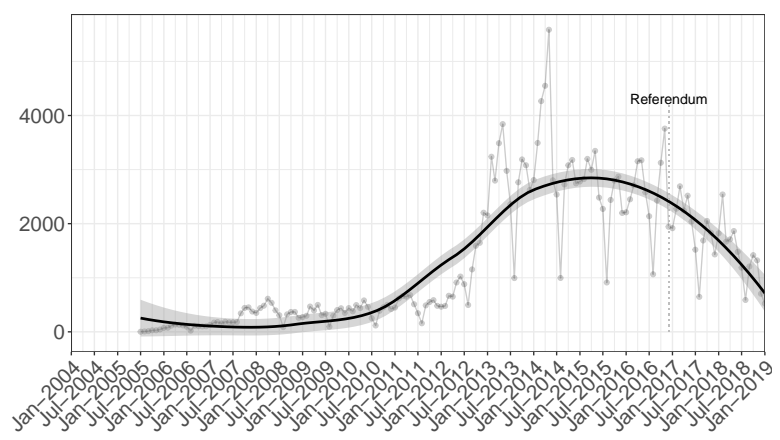

increase and acceleration of activity starting after the local elections in 2012. Panel (b) demonstrates that the number of events evolved in tandem and rose sharply from 2012. At the peak of M5S activity between 2012 and 2016, the monthly number of events reached about 3,000 on average, i.e. an impressive one hundred events per day scattered across the country. The seasonal pattern within years demonstrates the face validity of our data: activity consistently drops during summer holidays in August. M5S activity on MeetUp starts to decrease from late 2017 when Grillo eventually decided to reduce reliance on MeetUp and move supporters to an internal platform called Rousseau in order to "put order in the uncontrolled ocean of meet ups". 6

After retrieving all information on M5S grassroots activities, we use reverse geocoding techniques to aggregate exact event locations into politically relevant boundaries, i.e. municipalities ("comuni"). The original dataset on the event level is thus transformed into a time-varying municipality-level dataset of political grassroots activity. Figure 2 visualizes this procedure. The "heatmap" on the left reports each M5S event and its precise geographical location. Using these locations and a shapefile of Italian municipalities in $\mathbf{2 0 1 6}$, we then evaluated in which municipality each event took place. On the right side of Figure 2, we report the result of this matching exercise: 667 of 7,998 municipalities were exposed to M5S mobilization; the remaining 7,331 municipalities were not. Even though M5S mobilization is unsurprisingly visible in urban, highly populated municipalities - such as Rome, Milan, Florence and Naples - more provincial areas and more rural municipalities also experience a large number M5S events, especially in Northern Italy, Sardinia and Sicily.

Since each of our more than 200,000 events features a more or less detailed description of the

\footnotetext{
${ }^{6}$ Quoted from IL Fatto Quotidiano.
} 
(a) M5S mobilization, heatmap

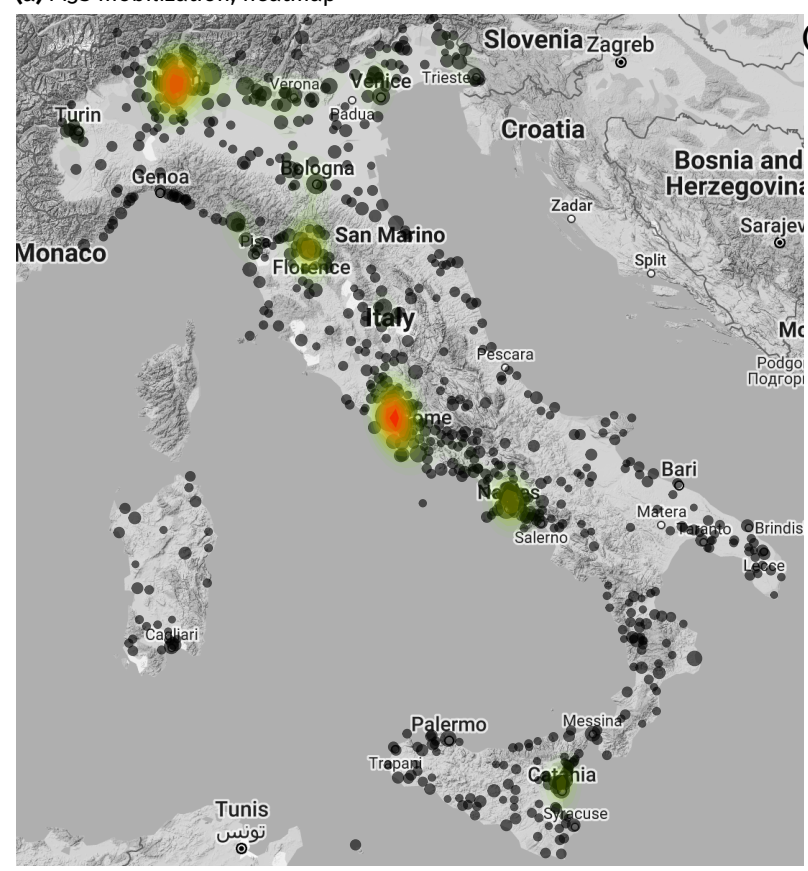

(b) M5S exposure per municipality (comune)

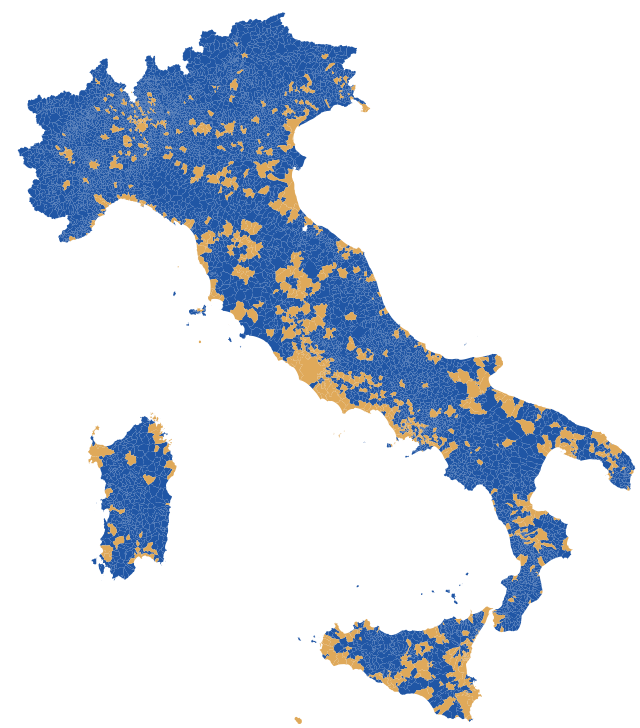

Note: On the left: heatmap and geo-location of all M5S events. On the right: map of Italian municipalities. Red municipalities are exposed to M5S meetings, blue municipalities did not experience any M5S events until 2016.

issues to be discussed, our data allows for a description of the content-wise aim of M5S meetings. A direct classification of single events into topics, e.g. environmental politics or the constitutional referendum, is not feasible because the descriptions are not always informative and often rather short. However, the overall corpus of text consisting of the pooled content of all descriptions still allows for an informative illustration of some of the movement's recurring key topics and how they have evolved over time.

Figure 3 shows the result of a simple text analysis of these descriptions. After standardized pre-processing of the text, we retrieved the 300 most frequent features by year. For the sake of simpler visualization, we manually categorized these top features into broader topics (Appendix A.2). First of all, the absolute number of texts across years reflects the overall activity of M5S MeetUp groups already discussed above. ${ }^{7}$ In terms of content, unsurprisingly, some of the movement's core issues such as community, deliberation, direct democracy, localization of economic structures and, especially in earlier years, environmental protection feature prominently. Perhaps most importantly for our purposes, the topic direct democracy is highly present across most years and dominates the

\footnotetext{
${ }^{7}$ We drop 2005 and 2006 for brevity. Top features are very similar to 2007 but on even lower levels of absolute numbers.
} 
Figure 3: M5S topics over time

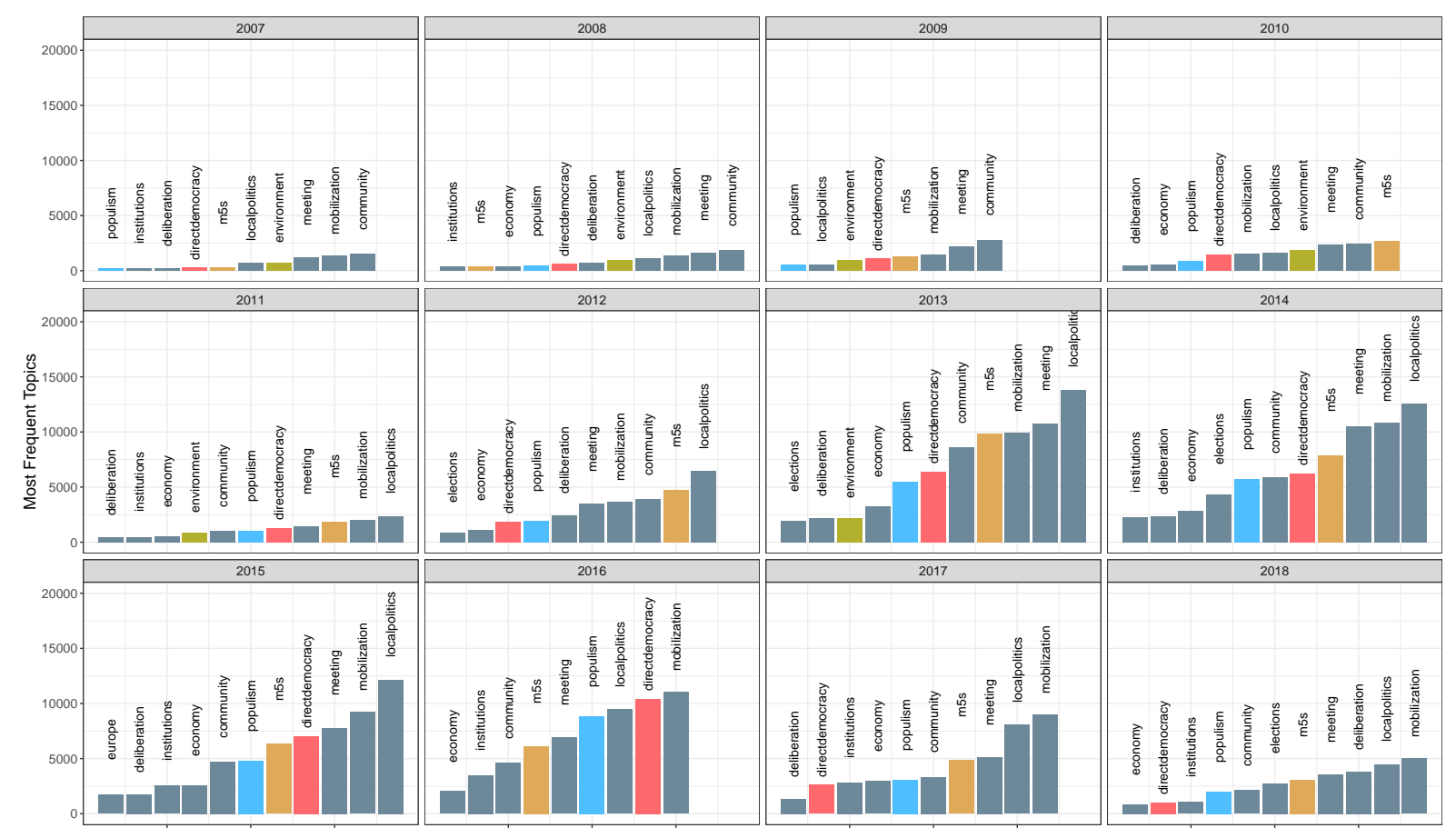

Note: 300 top features in event descriptions reclassified into broader topics, see Table A.2 in Appendix A.2.

M5S grassroots agenda in 2016 (mentioned over 10,000 times). This supports our point of departure that the M5S mobilized very actively and vocally against the constitutional reform. In fact, a further sub-analysis of the various terms related to direct democracy demonstrates the overwhelming importance of the referendum topic in 2016 (see Appendix Figure A.1).

\subsection{Operationalization: Local M5S activity}

From this unusually rich dataset on M5S activity, we create our main explanatory variable - exposure to M5S mobilization in each of the 7,998 Italian municipalities. For the main analysis, we focus on events taking place during the referendum campaign, which we define as running from the day the senate approved the reform and Renzi announced that he would resign if the reform was rejected (January 20, 2016) to the day of the referendum (December 4,2016$).{ }^{8}$ A total of 27,687 events took place during that period, which implies that the average M5S municipality experienced 37 campaign events. The most active local branch during that period was "Amici di Beppe Grillo Firenze" in Matteo Renzi's hometown with more than 400 organized events between January and December.

\footnotetext{
${ }^{8}$ In Appendix A.4.4, we report a robustness test using a shorter period to study exposure to M5S mobilization. Reassuringly, our key take aways remain unaffected by the coding decision.
} 
Since the raw numbers of events and participants are heavily right-skewed, we calculate the per eligible voter number of M5S event participants in a municipality. We approximate participation by the number of people who accepted the public invitation to an event (RSPVs) and log-transform the numerator due to right-skewed distributions of both activity and population. ${ }^{9}$ To avoid that our conclusions result from one specific operationalization, we also conduct analyses based on a simple binary measure - active local chapter during the referendum campaign $=1 ; 0=$ otherwise and a measure based on the number of events only, i.e. not weighted by participants (see Appendix Tables A.3 and A.7). Since we have precise information on the appointed date and time of every single event, we can vary the aggregation of events over time ${ }_{t}$ depending on the specific requirements of the various models. For example, we will be able to compare effects of M5S mobilization during the height of the campaign as defined above to long-term effects of cumulative M5S activity since the first day of a local chapter's existence.

It is important to note that the analyses reported below capture an intention to treat effect: The data does not allow us to capture which part of the population within a municipality attended the events organized by M5S. What we do know is that events took place in some municipalities, and that this makes it much more likely that the population is either directly (e.g. attending events) or indirectly (e.g. discussing events with friends who attended) affected by M5S mobilization. In addition, the individual-level data provides an opportunity to examine through which channels and events respondents received information during the referendum campaign (including "offline events organized via the web"). The respective results, which we report below, may be read as something that comes close to an actual manipulation test.

\section{Results}

\subsection{Municipality level: official electoral data}

For the municipality-level analysis, we collected official register data on the 2016 referendum outcome. Before delving into more complex estimations, our first part of the analyses relies on a simple t-test

${ }^{9}$ Formally, our explanatory variable is defined as follows:

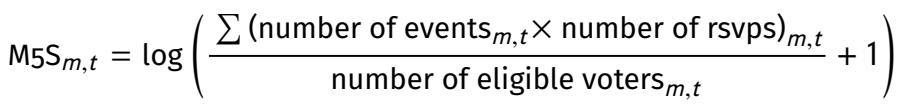

With $m$ indicating municipality and ${ }_{t}$ time of the survey wave. 
between municipalities exposed to/not exposed to M5S mobilization. Figure 4 plots a histogram across all municipalities (blue $=$ not exposed, red $=$ exposed). It becomes immediately visible that

Figure 4: Bivariate comparison between municipalities without and with M5S grassroots mobilization

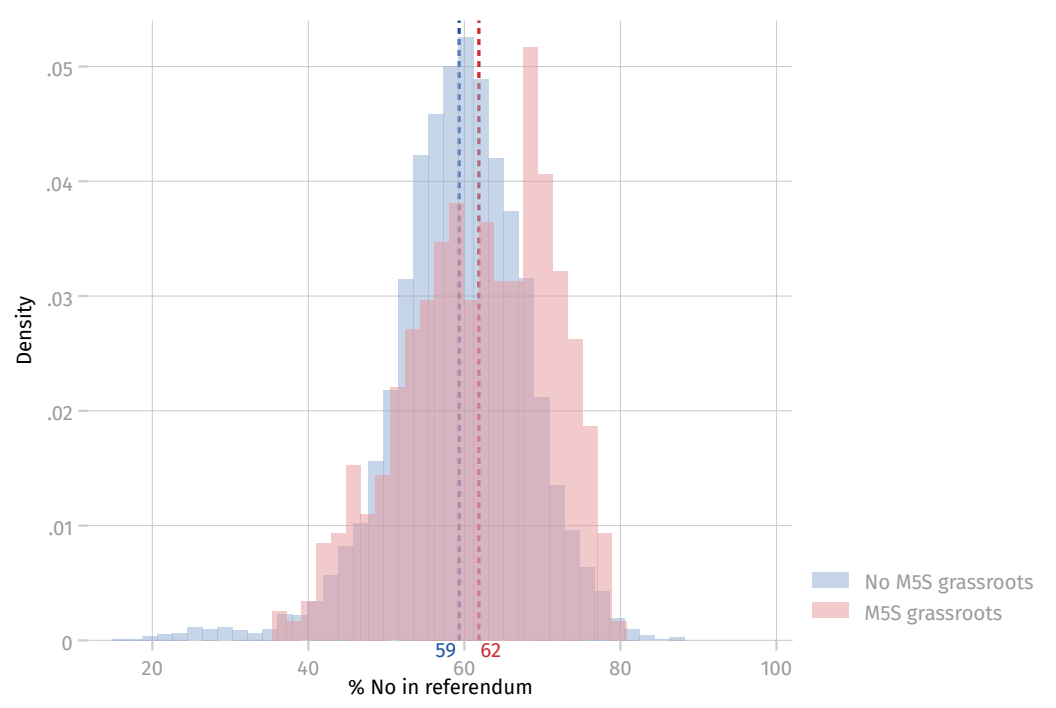

Note: The difference between the two distributions is statistically significant. The dashed lines report the mean for each distribution.

municipalities with an active M5S chapter on average were 3 percentage points more likely to vote No in the referendum.

Of course, other factors such as economic well-being or previous voting patterns might explain this difference. Thus, we also collected relevant covariates (income per capita, share unemployed, share university degree, share primary education and lower, share foreigners, population density) for each of the 7,998 municipalities in $2016^{10}$ to control for confounding economic and structural differences across municipalities affecting the referendum result along with M5S mobilization. Furthermore, we controlled for voting patterns in the last federal elections in 2013 when M5S parliamentarians first entered the bicameral institutions. We include the percentage of the population voting for M5S, Partito Democratico (PD) and turnout in each municipality at the 2013 federal elections. ${ }^{11}$

To formally test whether M5S grassroots mobilization predicts the share of No votes in the 2016

\footnotetext{
${ }^{10}$ The data stems from various sources: election data from Governo italiano Ministero dell'Interno; unemployment, foreigners from ISTAT; taxable income from Departemento della Finanze; education from Census data.

${ }^{11}$ To be more precise, we control for the percentage of the population voting for M5S in the chamber of deputies only. The reason for not controlling for the senate is that only voters older than 25 are allowed to vote for it. However, our findings remain robust when we control for votes in the senate and chamber of deputies
} 
referendum, we then estimate OLS models of the following form:

$$
y_{m}=\gamma{\mathrm{M} 5 \mathrm{~S}_{m}}+\beta X_{m}+\alpha_{p}+\epsilon_{m}
$$

where $\gamma$ indicates the coefficient of interest showing the effect of M5S exposure on the amount of No votes $y$ in each municipality $m ; \alpha_{p}$ are province fixed effects controlling away any time-invariant province characteristics; and $X$ is the set of municipality-level control variables outlined above. Since the referendum is a single cross-section, we cannot use municipality-level fixed effects nor cluster our standard errors on the municipality. Instead, we cluster our standard errors on the province-level - the next higher administrative level - to get hold of any province-specific correlations within the error term structure. ${ }^{12}$

Table 1 shows the results of the cross-sectional analysis on the municipality level. ${ }^{13}$ Again, we

Table 1: OLS estimates (municipality), does M5S grassroots mobilization predict referendum No-vote share?

\begin{tabular}{|c|c|c|c|c|c|c|c|c|}
\hline & \multicolumn{8}{|c|}{$\%$ No in referendum } \\
\hline & \multicolumn{4}{|c|}{ Binary } & \multicolumn{4}{|c|}{ Continuous } \\
\hline & (1) & (2) & (3) & (4) & (5) & (6) & (7) & (8) \\
\hline M5S activity $(0,1)$ & $\begin{array}{c}2.53 \\
(1.12)\end{array}$ & $\begin{array}{c}0.86 \\
(0.35)\end{array}$ & $\begin{array}{c}0.65 \\
(0.19)\end{array}$ & $\begin{array}{c}0.34 \\
(0.19)\end{array}$ & & & & \\
\hline M5S activity (cont.) & & & & & $\begin{array}{c}1.08 \\
(0.40)\end{array}$ & $\begin{array}{c}0.35 \\
(0.13)\end{array}$ & $\begin{array}{c}0.21 \\
(0.08)\end{array}$ & $\begin{array}{c}0.19 \\
(0.09)\end{array}$ \\
\hline M5S: \% votes 2013 & & & $\begin{array}{c}0.25 \\
(0.05)\end{array}$ & & & & $\begin{array}{c}0.25 \\
(0.05)\end{array}$ & \\
\hline Constant & $\begin{array}{l}59.32 \\
(0.66)\end{array}$ & $\begin{array}{l}59.45 \\
(0.03)\end{array}$ & $\begin{array}{c}76.24 \\
(2.06)\end{array}$ & $\begin{array}{l}61.46 \\
\text { (0.10) }\end{array}$ & $\begin{array}{l}59.33 \\
(0.66)\end{array}$ & $\begin{array}{l}59.46 \\
(0.02)\end{array}$ & $\begin{array}{l}76.26 \\
(2.06)\end{array}$ & $\begin{array}{l}61.46 \\
(0.10)\end{array}$ \\
\hline Province FE & & $\checkmark$ & $\checkmark$ & $\checkmark$ & & $\checkmark$ & $\checkmark$ & $\checkmark$ \\
\hline Controls & & & $\checkmark$ & & & & $\checkmark$ & \\
\hline Entropy balanced & & & & $\sqrt{-}-2$ & & & & $\sqrt{-1}$ \\
\hline$\overline{\mathrm{O}} \overline{\mathrm{bs}}------$ & $\overline{7994}$ & $\overline{79} \overline{9} 4^{-}$ & $\overline{780} \overline{4}$ & $\overline{7804}$ & $\overline{7} \overline{9} 9 \overline{4}$ & $7 \overline{994}$ & $78 \overline{0}^{-}$ & $\overline{7} 8 \overline{0} \overline{4}^{-}$ \\
\hline Provinces & 110 & 110 & 110 & 110 & 110 & 110 & 110 & 110 \\
\hline $\operatorname{adj} . R^{2}$ & 0.01 & 0.55 & 0.71 & 0.72 & 0.01 & 0.55 & 0.71 & 0.72 \\
\hline adj. $R^{2}$ (within) & 0.01 & 0.00 & 0.34 & 0.00 & 0.01 & 0.00 & 0.34 & 0.00 \\
\hline RMSE & 8.72 & 5.86 & 4.69 & 4.72 & 8.72 & 5.86 & 4.69 & 4.71 \\
\hline
\end{tabular}

\footnotetext{
${ }^{12}$ Note that from a methodological point of view, clustering is not necessarily needed in this case. Results without clustering are substantively identical but have smaller standard errors.

${ }^{13}$ In four municipalities nobody participated in the referendum according to the official data. Thus, we analyze the results for 7994 municipalities.
} 
first rely on a simple binary comparison between exposed and unexposed municipalities in models (1)-(4). The first model reporting a 2.53 percentage point increase of No votes in M5S municipalities can thereby be understood as a formal test of the comparisons we drew in Figure 4. Subsequently, we introduce province fixed effects in model (2) and our set of controls in model (3). While the difference of M5S exposure remains statistically significant, the size of the effect shrinks considerably to 0.65 percentage points. This means that after control for socioeconomic and voting characteristics of each municipality, municipalities with active M5S chapters are about half a percentage point more likely to vote No in the referendum. Using the continuous measure as outlined above results in similar conclusions (models (5)-(7)).

Of course, M5S mobilization is not randomly assigned. Municipalities experiencing M5S mobilization might vary on several factors, which might explain the actual differences between both mobilization during and voting No at the referendum. To address this concern, we use entropy balancing to match unexposed with exposed municipalities (Hainmueller 2012). ${ }^{14}$ We visualize the outcome of this procedure in Figure 5. For the raw data we find significant differences between

Figure 5: Balance statistics regional data, raw and after entropy balancing

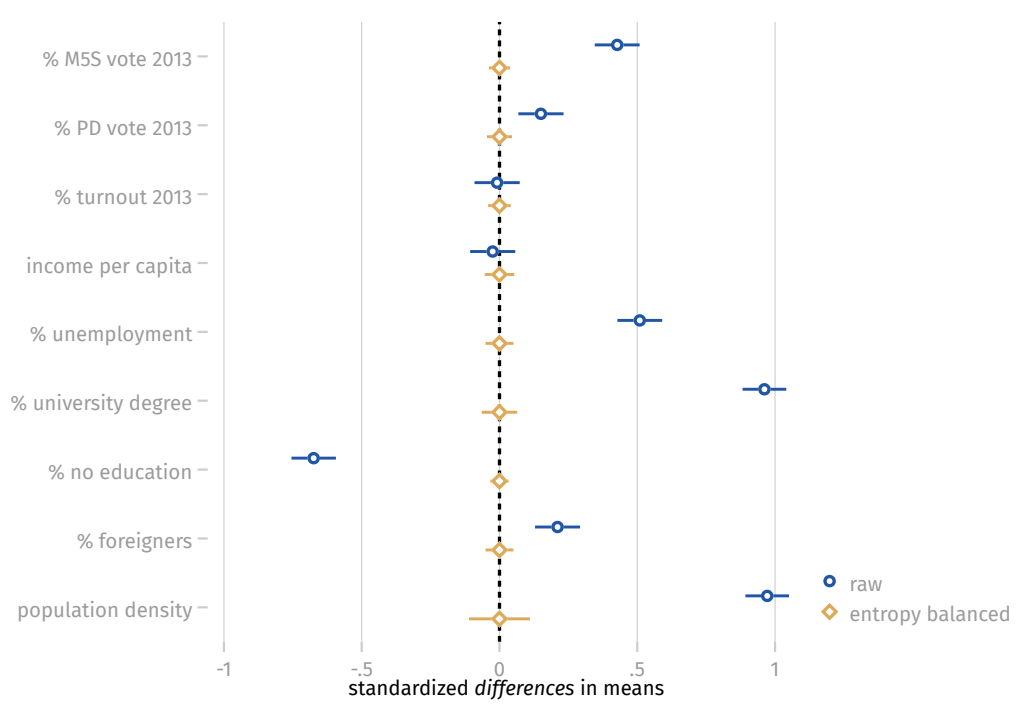

Note: Reported are OLS estimates surrounded by $95 \%$ confidence intervals. "Raw" is a model without any re-weighting, "entropy balanced" re-weights the sample according to the weights retrieved from an entropy balancing model discussed in the paper.

\footnotetext{
${ }^{14}$ We also used nearest neighbor matching. However, we only achieve balance and have enough power to estimate our models with a caliper of 1 or larger. Even in this model, $2 / 3$ of the cases are dropped from the analysis. However, the results are virtually the same as the ones we report here from entropy balancing.
} 
municipalities exposed to M5S activities and municipalities that were not exposed. However, as the orange point estimates in Figure 5 indicate, with entropy balancing we are able to retrieve full balance in all observed covariates between exposed and unexposed municipalities. Models (4) and (8) rely on the weights stemming from entropy balancing and re-estimating our models. Again, we find significant differences between exposed and unexposed municipalities - albeit in the case of the binary measure significant on the $10 \%$ level only with $p=0.087$. Notice, however, that in the Appendix we use a much more conservative definition of the campaign period analyzed here. These models report higher coefficients and remain significant throughout below the $5 \%$ threshold (Appendix A.4.4).

\subsection{Individual level: the ITANES panel}

We complement our municipality-level results with an analysis of individual-level panel data. This approach comes at the cost of measurement error regarding the referendum outcome, but it allows us to examine within-municipality and within-subject effects of M5S grassroots mobilization. We rely on the ITANES Referendum Panel (2016). The Italian National Election Study has carried out large sample surveys for all major elections and referendums in Italy since the 1970s. While the location of each respondent enables us to match respondents to actual exposure to M5S mobilization within their municipalities, the panel structure guarantees that we can estimate within-person changes on voting No at the referendum. The ITANES panel 2016 collected data on 3,050 respondents in two waves - one approximately six months before the referendum, one immediately thereafter. Besides the usual sociodemographic and socioeconomic information, the panel asks respondents about their intention to vote (pre wave) and their actual vote (post wave) in the referendum. The panel also includes information about the political preferences of each respondent - past vote choice, political interest, or left-right self-placement. Moreover, the panel structure facilitates combination of the 2016 waves with earlier post-election waves. Thus, we can measure several covariates - such as voting or political interest - long before Renzi introduced the idea of a referendum, which hedges against post-exposure bias. Taken together, the ITANES data enables a rigorous analysis of the impact of M5S mobilization on within-person changes of preferences about the referendum.

Using the data as outlined above based on the two-wave ITANES referendum panel, we first 
estimate a series of fixed effect OLS regression models of the following form:

$$
y_{i m t}=\gamma \mathrm{M} S \mathrm{~S}_{m t}+\beta X_{i t}+\tau_{t}+\lambda_{m}+\epsilon_{i m t}
$$

where again $\gamma$ indicates the coefficient of interest showing the effect of M5S exposure on voting No in the referendum for each respondent ${ }_{i}$ nested into municipality ${ }_{m}$ and two survey waves ${ }_{t}$. The M5S campaign variable is operationalized analogously to the previous version but redefined such that the volume of M5S grassroots activity is matched with the survey timing. ${ }^{15} \tau_{t}$ and $\lambda_{m}$ are fixed effects for municipalities and survey waves respectively; $X_{i t}$ a set of individual-level control variables outlined above. Thus, we now only leverage the variation of M5S exposure within municipalities. This means that we factually model the change within each respondent regarding their referendum vote. We use multi-way clustering by respondent-ID - each respondent is observed in two waves and by municipality (exposure assignment). ${ }^{16}$ Certainly, the ITANES panel is not representative of the population within each municipality. However, below we will mainly focus on changes within municipality and respondent. This means that internal validity of our design is not affected by the lack of representatives on the municipality level.

Table 2 reports the main findings of these model specifications based on the ITANES data. More specifically, in models (1)-(3), we subsequently add municipality fixed effects, wave fixed effects and our set of control variables reported in the note of the table. The findings of these individual level models correspond nicely with our municipality-level analyses. Again, we find a statistically significant effect of M5S grassroots mobilization: a one-unit increase in M5S activity corresponds to a 7-8 percentage point increase in voting No at the referendum.

In model (4), we then replace the municipality fixed effect with an individual-level fixed effect. ${ }^{17}$ This is the most conservative model we estimate throughout the paper since it only leverages the variation in M5S grassroots mobilization and voting No at the referendum within each respondent. We still find a 7 percentage point increase in voting No.

In model (5) and (6), we again apply entropy balancing. We match respondents only on pre-

\footnotetext{
${ }^{15}$ For the first wave, we use all events during the referendum campaign until the fielding dates of the survey; for the second wave, we rely on all events since the start of the referendum campaign and the day of the referendum.

${ }^{16}$ Clustering by municipality only results in virtually identical standard errors.

${ }^{17}$ This also means that we cannot introduce any individual-level controls as these are all time invariant and, thus, drop out of the equation.
} 
Table 2: OLS estimates (individual), does M5S grassroots mobilization predict individual referendum voting?

\begin{tabular}{|c|c|c|c|c|c|c|}
\hline & \multicolumn{6}{|c|}{ Vote: 'No' in referendum } \\
\hline & (1) & (2) & (3) & (4) & (5) & (6) \\
\hline M5S: referendum & $\begin{array}{c}0.07 \\
(0.02)\end{array}$ & $\begin{array}{c}0.08 \\
(0.02)\end{array}$ & $\begin{array}{c}0.07 \\
(0.03)\end{array}$ & $\begin{array}{c}0.07 \\
(0.02)\end{array}$ & $\begin{array}{c}0.07 \\
(0.03)\end{array}$ & $\begin{array}{c}0.07 \\
(0.03)\end{array}$ \\
\hline M5S voter in $2013(0,1)$ & & & $\begin{array}{c}0.07 \\
(0.03)\end{array}$ & & & \\
\hline Constant & $\begin{array}{c}0.39 \\
(0.02)\end{array}$ & $\begin{array}{c}0.94 \\
(0.07)\end{array}$ & $\begin{array}{c}0.79 \\
(0.10)\end{array}$ & $\begin{array}{c}0.40 \\
(0.02)\end{array}$ & $\begin{array}{c}0.42 \\
(0.02)\end{array}$ & $\begin{array}{c}0.42 \\
(0.02)\end{array}$ \\
\hline Wave FE & $\sqrt{ }$ & $\checkmark$ & $\checkmark$ & $\checkmark$ & $\checkmark$ & $\sqrt{ }$ \\
\hline Municipality FE & $\sqrt{ }$ & $\checkmark$ & $\sqrt{ }$ & & $\checkmark$ & \\
\hline Socioeconomic controls & & $\checkmark$ & $\checkmark$ & & & \\
\hline Political controls & & & $\checkmark$ & & & \\
\hline Individual FE & & & & $\sqrt{ }$ & & $\checkmark$ \\
\hline Entropy balanced & & & & & $\sqrt{ }$ & $\checkmark$ \\
\hline$\overline{\mathrm{O}} \overline{\mathrm{bs}}--\cdots$ & $\overline{5} 254^{-}$ & $\overline{5206}$ & $4070^{-}$ & $5 \overline{16} \overline{6}$ & $4 \overline{0} \overline{0}$ & $\overline{4}{ }^{-} 12-$ \\
\hline Municipalities & 1016 & 1006 & 856 & 1012 & 856 & 855 \\
\hline $\operatorname{adj} . R^{2}$ & 0.17 & 0.25 & 0.30 & 0.51 & 0.26 & 0.57 \\
\hline $\operatorname{adj.} R^{2}$ (within) & 0.00 & 0.09 & 0.14 & 0.00 & 0.00 & 0.00 \\
\hline RMSE & 0.45 & 0.43 & 0.42 & 0.35 & 0.43 & 0.33 \\
\hline
\end{tabular}

Note: Clustered standard errors by individual $\times$ municipality in parentheses. Controls omitted from table: economy retrospective (1-5), unemployed $(0,1)$, female $(0,1)$, age (18-88), education (1-7), religiosity $(0,1)$, PD voter in $2013(0,1)$, political interest (1-4), talk politics (1-6), explicitly no left-right self-placement $(0,1)$, politics too complex (1-4), internal efficacy (1-4). For entropy balancing, we use only variables asked in the 2013 post-election study as outlined in Figure A.9.

treatment covariates in order not to introduce post-treatment bias. ${ }^{18}$ Reassuringly, we do not find any meaningful differences for respondents' vote choice in 2013, refusal to place themselves on the left-right scale ${ }^{19}$, internal efficacy or even political interest (see Figure A.9 in the Appendix). At the same time, the figure shows clear differences between exposed and unexposed respondents, for instance in education. To address this issue, we again rely on entropy balancing. After balancing, we do not observe any differences between respondents exposed to and respondents not exposed to M5S mobilization in their municipalities. Model (5) and (6) then re-estimate models (3) and (4) respectively by applying the entropy weights. Again, we find a positive effect of $\mathrm{M}_{5} \mathrm{~S}$ grassroots activity

\footnotetext{
${ }^{18} \mathrm{~A}$ causal interpretation of our panel-data findings relies on the parallel trends assumption, i.e. we can observe parallel trends in referendum voting between the respondents who do not experience M5S grassroots mobilization and respondents who do. Given that the 2016 referendum is a single event, and respondents also are exposed to M5S grassroots mobilization on the referendum before the first wave of the ITANES panel, we cannot directly test this assumption by comparing pre-treatment trends in the outcome as it is usually done. However, we can leverage the information we can retrieve from respondents who were already interviewed in the 2013 post-election study.

${ }^{19}$ Refusing self-placement on this scale is one of the strongest predictors of M5S voting. Therefore, the ITANES panel explicitly asks respondents if they do not see themselves placed at all in the left-right general space, with $16 \%$ of respondents using this option.
} 
on voting No at the referendum, statistically significant on conventional levels ( $p$-value $=0.027$ ).

A major difference between our individual- and regional-level findings is the magnitude of the effect. Overall, we find substantially larger effects for the individual-level analyses. A one-unit increase in M5S mobilization is associated with a 0.18 percentage point increase in No votes in the regional-level analyses, while we find a 7-percentage point increase in Nos on the individual level. However, given our transformation of the continuous variable, a one-unit increase does not have a very straightforward interpretation. To nevertheless outline the substantial effect of our results, let us imagine a town with 100 inhabitants in which not a single M5S event is organized. In this case, our continuous measure is 0 , as there is no M5S mobilization and consequently no change in No votes (equals a prediction of $61.43 \%$ No votes nationwide). Now let us change that: imagine the same town in which $10 \%$ (10 inhabitants) of the population take part in one single event organized by a local M5S group. This corresponds to a value of 0.41 on our continuous M5S measure. If this increase in mobilization happened nationwide, it would increase No votes by 0.07 percentage points (equals a prediction of $61.5 \%$ No votes nationwide). At first sight, this may sound like a small increase, but this very realistic change in mobilization we discuss here is just about half as large as an increase by a standard deviation on our independent variable. This is just to say that what might sound like a small increase appears to be a realistic estimate for mobilization effects of locally organized events across the nation. Again, keep in mind that the same scenario would result in a major effect if we relied on the individual-level panel data: an increase in No votes of 3 percentage points. The difference between the two data-sets is then largely explained by the major opinion shift that occurred during the referendum campaign. As discussed elsewhere (Ceccarini and Bordignon 2017: 293), almost all voters supported the reform at the beginning of the campaign, including $66 \%$ of M5S supporters. This changed drastically during the campaign, and in particular M5S voters turned in large numbers to the No camp. Similarly, in the first wave of the ITANES panel, only $33 \%$ of the voters suggest that they want to vote No at the referendum, while $54 \%$ say they voted No in the post-referendum wave. Our analysis based on the actual referendum result does not capture this drastic cross-time shift; the analysis can only be based upon cross-sectional variation. 


\section{Channels}

\section{Spatial (non-)contagion of place-based campaigning}

A fundamental theoretical and empirical question emerging from our main result is whether the effects we report are tied to M5S activities within a municipality or subject to spillover patterns to adjacent municipalities. In more technical terms, we based our analyses upon the stable unittreatment value assumption (SUTVA), meaning that there are no spillover effects from M5S activity in nearby municipalities. Beyond research design issues, this is a theoretically highly relevant question. We expect place-based campaigning to be particularly effective due to social network effects and peer pressure and hence argue that it is primarily local grassroots activity that affects the referendum outcome. By necessity, this means that we should not find large spillover effects to adjacent municipalities. Otherwise, our results would imply a de-localized effect. Such a more general effect is a likely alternative given the importance of social media tools in modern campaigns and particularly for the M5S.

Thanks to the detailed spatial disaggregation of our data, we can directly assess spillover effects and, hence, the plausibility of the SUTVA assumption, by calculating the total volume of M5S activity in all adjacent municipalities for formally unexposed municipalities. To give an example, the municipality Giardinello near Palermo on Sicily experienced no M5S mobilization within its boundaries, whereas adjacent municipalities experienced a total of 57 M5S events during the referendum campaign. Using this information instead of within-municipality exposure, we re-ran our models for (a) all municipalities and (b) only municipalities that never experienced M5S mobilization (Appendix Table A.8). We use the same empirical setup and variable operationalization as discussed above.

Figure 6 reports the key findings from this analysis. It is clear that we do not find any significant effect by adjacent M5S mobilization. If we include our set of controls, the adjacent effect is estimated as a precise null effect. In turn, our main findings based upon local M5S activities remain unaffected when we control for adjacent mobilization. We interpret this as strong evidence that M5S can mobilize locals to vote No at the referendum, and that this mobilization heavily relies on direct, local grassroots rather than universal trends driven by an elite-based, national campaign against the reform.

The detailed questionnaire of the ITANES panel allows us to go one step further and examine even 
Figure 6: How does local M5S grassroots campaigning matter?
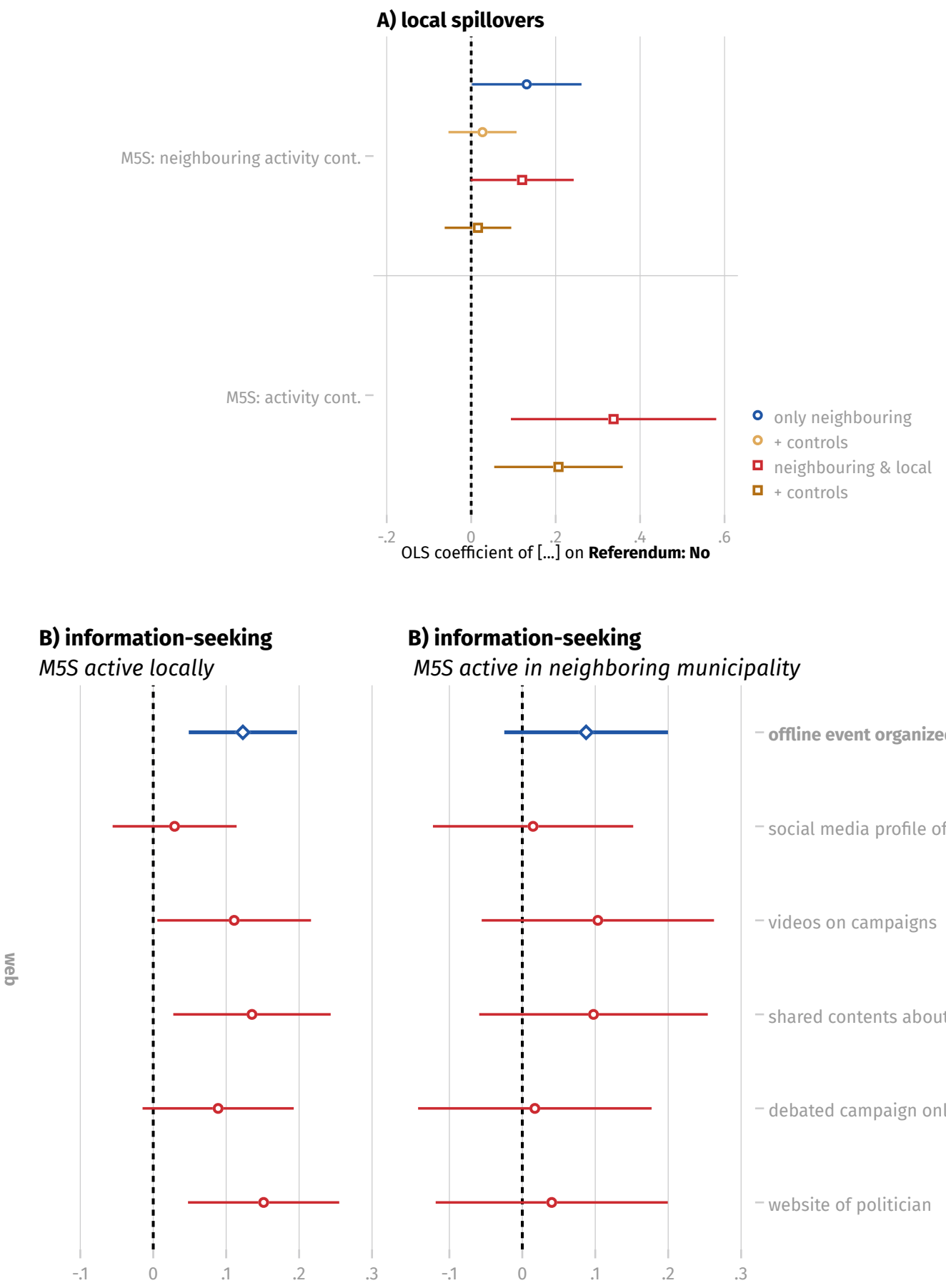

B) information-seeking M5S active in neighboring municipality

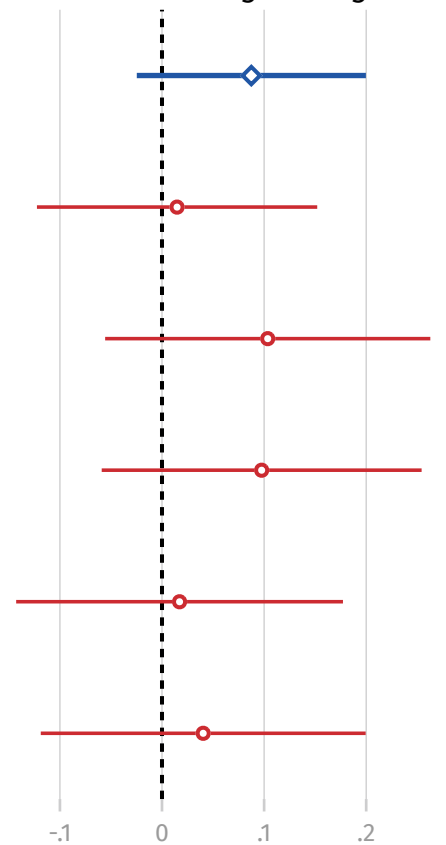

offline event organized via web

- social media profile of party

- videos on campaigns

- shared contents about campaign

debated campaign online

website of politician

from less to more frequently used (1-4)

Note: Reported are OLS estimates surrounded by $95 \%$ confidence intervals. The regional models use the full set of controls discussed above along with province fixed effects and standard errors clustered by province. The individual level models are based on the post-referendum wave only using the full set of pre-wave controls reported in Figure A.9. Full results and specification for Figure $6 \mathrm{~A}$ ) can be found in Appendix A.6.1.

Figure $7 \mathrm{~b}$ relies on the post-wave of the individual-level analysis only. The models include neither individual nor wave fixed effects. Instead we use province fixed effects and a binary measure ' 1 ' if a municipality had an active M5S chapter (= M5S locally active) and a measure ' 1 ' if a neighboring municipality had an active M5S chapter (= M5S active in neighboring municipality). For the models reported in 'M5S active in neighboring municipality', we only rely on municipalities that did not have a locally active M5S chapter. 
more subtle forms of potential spillover effects of the ways citizens gather information about the referendum. As outlined in the theoretical section, M5S activities are likely to inform citizens about the referendum and shift attitudes through a norm conformity mechanism within local social networks. The absence of spillover effects with respect to the referendum result confirms this expectation. Building on this previous analysis, we now look at a more conservative indicator of spillover effects by comparing respondents' information-seeking behavior in municipalities with M5S grassroots activity compared to respondents in formally unexposed but adjacent municipalities. This analysis relies on the post-referendum wave only, which unlike the pre-referendum wave contains a rich set of questions about information seeking by each respondent during the referendum campaign.

Panel B) in Figure 6 reports the findings from these estimations. In line with our expectations, the coefficients on the left demonstrate that a local M5S campaign goes hand in hand with more active online information seeking about the referendum. Residents in municipalities exposed to M5S campaigning use a variety of online resources, including campaign videos, online debates and websites of politicians. Perhaps most importantly for our purposes, they are more likely to use online sources to get information about events that ultimately take place offline, i.e. exactly the logic of the MeetUp platform. This finding hence supports the chain of events that characterize M5S mobilization as outlined above. M5S organizes online but creates an extensive offline feedback loop in terms of mobilization and affecting public preferences; they manage to effectively connect the on- with the offline sphere. Mirroring the analysis in Panel A), the right-hand side of Figure 6 examines the extent to which these effects on individual information seeking spill over to residents of adjacent but formally unexposed municipalities. Again, there is no indication of spatial contagion of M5S campaigns. Thus, this auxiliary analysis not only provides additional insights about the underlying mechanisms between M5S campaigning and the referendum result but also highlights that the particular effectiveness of place-based campaigning is rooted in highly local social networks.

\section{Who is affected by M5S grassroots activities?}

A second question we discussed in our theoretical section is who exactly are the people affected by local M5S chapters? First, we suggested that events can be differentiated into those that seek to organize the existing base and those that seek to affect bystanders. To approximate these types 
of events, we recoded our data into outdoor (bystander effect) and indoor (preaching to the choir) events relying on the location description provided by MeetUp (more details Appendix A.3).

In Panel A) Figure 7 we test whether indoor and outdoor events have different effects on the referendum result relying on regional as well as individual level data. ${ }^{20}$ We then report three models using the full set of controls and fixed effects discussed above. In the first model, we rely on indoor events as the key independent variable; in the second model, we rely on outdoor events; in the final model, we introduce both measures as independent variables in a single model. Interestingly, we do not find any effects of indoor events on the referendum results. Much in line with our theoretical argument, this suggests that these types of events are likely to preach to the choir and unable to mobilize numerically relevant opposition against the reform. In contrast, we do find significant effects of outdoor activities by local M5S chapters, suggesting that they can successfully mobilize citizens within the broader social network if events are organized in public spaces.

A final relevant aspect is the ideological predisposition of the bystanders who can be mobilized. In line with much of the traditional campaigning literature, we would expect that voters who already feel close to the aims of the movement are particularly prone to respond to its activities. We test this by interacting the M5S exposure variable with respondents' reported voting after the 2013 Italian federal election. Theoretically, we would expect a significant interaction effect between previous M5S voters and exposure to M5S grassroots activity, and this is indeed what we find. Panel B) in Figure 7 reports the marginal effect of this interaction. There is a significant interaction effect for $\mathrm{M}_{5} \mathrm{~S}$ votes, but no impact among supporters of other parties, irrespective of their stance on the referendum (see Table A.10 in the Appendix).

This additional analysis adds nuance to our main finding by demonstrating that the $\mathrm{M}_{5} \mathrm{~S}$ grassroots campaign against the reform was particularly effective among citizens who are sympathetic to the cause of the movement and have voted for M5S in the past. ${ }^{21}$

An alternative explanation for an increasing No-vote share is an activation effect, i.e. successful

\footnotetext{
${ }^{20}$ In Appendix A.7, we also discuss the differences between both types of events. We show that outdoor events have fewer RSVPs, which further underpins our argument that these events tend to mobilize bystanders. For more information please see Appendix A.7.

${ }^{21}$ The campaign also used what the traditional literature calls reinforcement, i.e. it worked via a complementary, hypothetical channel, which we cannot directly assess, to strengthen like-minded citizens' preference for their initial position. Such reinforcement is politically highly relevant as it serves the important "purpose of preserving a prior decision" instead of initiating another decision (Lazarsfeld, Berelson, and Gaudet 1948: p. 87).
} 
Figure 7: Who is affected by M5S grassroots?
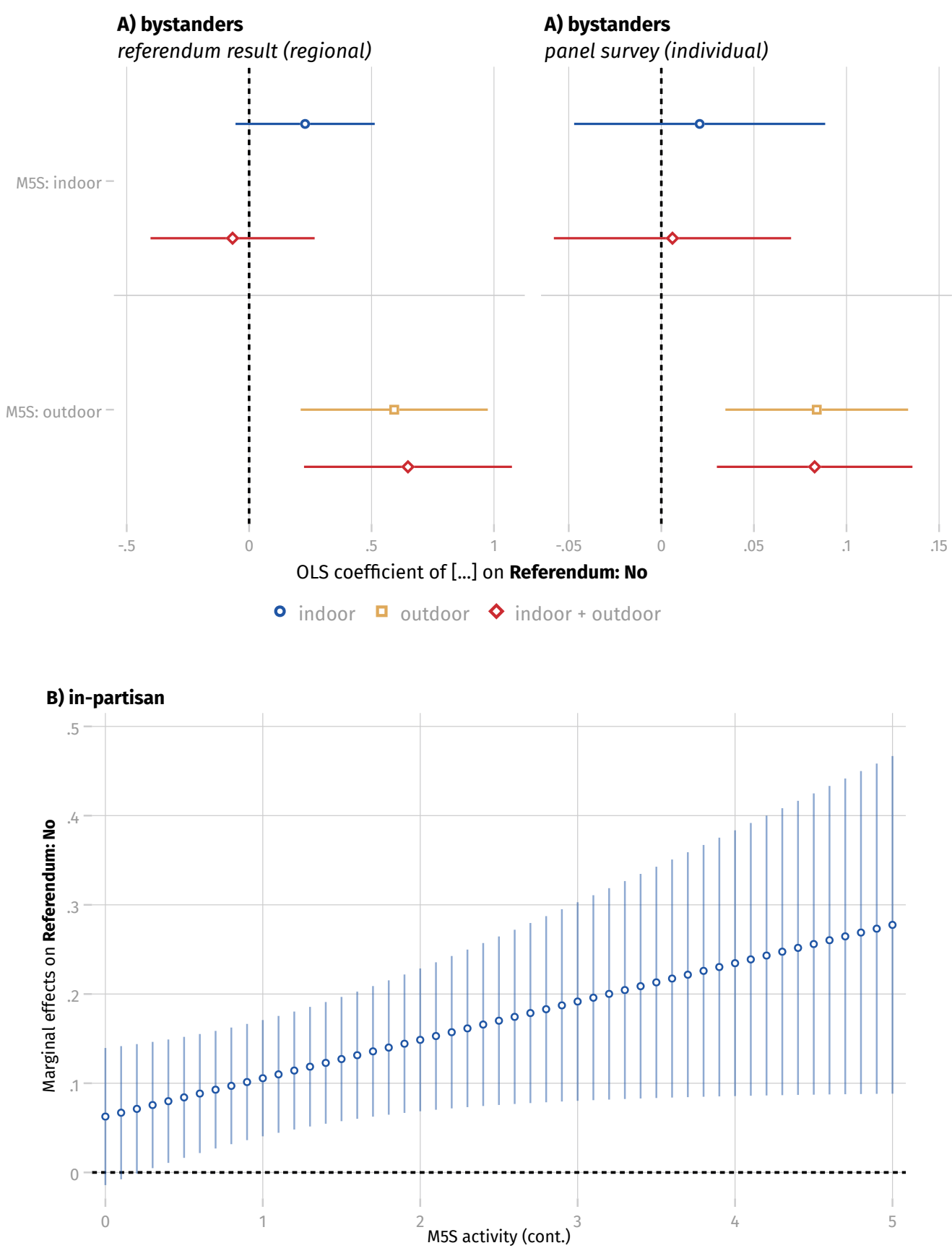

Note: Reported are OLS estimates surrounded by $95 \%$ confidence intervals. The regional models use the full set of controls discussed above along with province fixed effects and standard errors clustered by province. The individual level models use municipality and wave fixed effects along with the full set of controls reported in Figure A.9.

Full results and specification for Figure $7 \mathrm{~A}$ ) can be found in the Appendix A.7.

Full results and specification for Figure 7 B) can be found in the Appendix A.6.2. 
mobilization of inactive voters. In order to test for this alternative explanation, we examined the impact of M5S activity on turnout. We re-ran our entire analysis on both regional and individual level with regard to participation in the referendum rather than its outcome. In contrast to the robust impact on the No-vote share, the effects of M5S exposure on turnout are weak and inconclusive. These results hence lend little support to a clear-cut interpretation of the results as a mobilization story. ${ }^{22}$ In line with Pons (2018), we conclude that persuasion rather than activation of non-voters is the key channel through which M5S activity affected referendum results.

\section{Robustness and causality}

We conducted several additional tests to examine the robustness and causality of the main result that M5S campaigning increased the local No-vote share in the 2016 referendum. First, given that M5S mobilization is less common for most rural and more isolated provinces, the immediate question is whether and how the M5S effects vary across provinces. Similarly, other parties also campaigned against the reform, specifically in the Northern regions of Italy. Our main results already control for population density, but the findings might still be driven by a few more urbanized and more politicized provinces. To address this concern, we used a jackknife test in the municipality level analysis that drops each province once and re-estimates our models (Appendix A.4.2). Each of these 110 models reports a significant effect, and the pooled effect of this test is similar in size to the results reported here.

Second, questions of reversed causality and omitted variable bias still linger. Our matching approach relies on the assumption that we observe all key characteristics driving M5S mobilization. However, some unobserved factors like local norms or specific traditions of political contestation might drive both local M5S activity and opposition to the referendum (common cause). Although the individual panel analysis largely addresses these concerns, we also approach this methodologically challenging problem on the regional level. To do so, we first estimate a set of placebo models. Since we have rich information about M5S mobilization also after the 2016 referendum, we can use it to estimate whether future M5S mobilization affects the past 2016 referendum results. The idea behind

\footnotetext{
${ }^{22}$ At least on the regional level, mobilization of opponents and demobilization of supporters may cancel each other out, which would mask underlying mobilization effects. However, we can test for potential deterrence of initial supporters of the referendum or partisans of other parties at the individual level. The results (see Appendix Table A.10) do not support such a more complex mobilization mechanism either.
} 
this placebo test is that we should not expect any effects of future mobilization on past political results - specifically for municipalities that have not yet experienced M5S mobilization. If this was the case, we would have strong reason to assume that other factors besides M5S grassroots activity drive our findings. Appendix A.4.3 reports the findings of these placebo models. Reassuringly, we do not find any significant effects of future M5S mobilization on the 2016 referendum results.

In addition, we propose an instrumental variable (IV) design to further support a causal interpretation of our main result. We restrict ourselves to a brief, intuitive summary of the instrument at this point but provide a detailed description of our approach and the credibility of its underlying assumptions in Appendix A.4.5. In essence, we leverage the fact that M5S mobilization was predominantly organized online, which means that internet access became a precondition for keeping informed about and being able to participate in M5S events. ${ }^{23}$ Importantly, broadband access is to a certain extent quasi-randomly assigned in Italy because access to ADSL internet depends heavily on the pre-existing telecommunication infrastructure (Campante, Durante, and Sobbrio 2018; Schaub and Morisi 2020).

We can leverage this fact as quasi-random variation to the earlier success of local M5S mobilization. More specifically, we use the rich information we gathered for each M5S group to estimate the day a M5S group came into existence in each Italian municipality. This variable is predictive of M5S mobilization during the 2016 referendum campaign, meaning that M5S groups that came into existence earlier are more likely to mobilize more successfully today - even though the original topics and intentions of M5S's early days are no longer relevant for most groups we study during the referendum. We then interact this historical information with the distance of each municipality to the the closest urban group stage (UGS, the technical term being "higher-order telecommunication exchange"). The intuition behind this interaction is that the timing when M5S first mobilized in a given municipality is to some extent contingent on the volume of broadband internet access provided in that municipality. Appendix A.4.5 reports the findings of this instrumental variable approach along with crucial tests of the instruments' first stage, tests of the instruments' independence and an extensive discussion of the exclusion restriction. Consistent with our previous results, we find a significant and positive

\footnotetext{
${ }^{23}$ From today's perspective, this might appear as a negligible impediment, but it was a major issue when M5S started mobilizing from 2005. According to official data from the OECD and the Italian communication ministry, only about every third Italian household had access to broadband internet at the time, and although mobile internet already existed, it was far from being commercialized.
} 
effect of M5S mobilization on No votes in the referendum.

\section{Conclusion}

This article has demonstrated the continued relevance of traditional partisan grassroots organization and bottom-up mobilization of potential supporters even in an era with omnipresent online campaign tools and social media. Drawing on unique data from Italy, we show that the political on-the-ground activities of the Movimento Cinque Stelle, a major challenger party that has rapidly risen to power, led to noticeable effect on voting during the constitutional referendum in 2016. The robust impact of locally rooted M5S campaigning on the referendum outcome highlights the crucial role of social networks in amplifying the effectiveness of a campaign.

Moreover, we carefully investigate the channels through which this general mobilization effect comes into play. Auxiliary analyses show that the direct effect on the referendum result is driven by hyper-local mobilization without spillovers into neighboring municipalities and a reinforcement of like-minded citizens mobilized at public outdoor events. Our results are robust to a set of further analyses and represent plausibly causal effects that hold up in a generalized difference-in-difference and instrumental variable design. As in any research design, each of our analyses is based upon a set of assumptions - e.g. excludability assumptions - that we test as adequately as possible, but they remain assumptions and approximations. Yet, the richness of our analyses and the amount of robustness tests portray a solid and stable picture. Based on fine-grained geo-located data along with national referendum results and a rich panel dataset, these empirical findings go well beyond existing research on partisan grassroots mobilization. They also add to the important strand of experimental research on campaigns, which tends to study more isolated mobilization efforts compared to our analysis, which covers nation-wide grassroots activities during a constitutional referendum campaign.

Of course, our results are based on one referendum in a particular political environment. We do not claim that they can be blindly applied to any other campaign situation. The generalizability of the findings certainly depends on various contextual factors, which might provide fruitful avenues for future research. Potentially important context conditions include (a) whether the party at hand is an established organization or a newish label with lots of grassroots enthusiasm, (b) whether the campaign aims at shifting a binary referendum outcome or winning an election, or (c) whether 
a choice takes place in a situation characterized by widespread dissatisfaction with the political system, where many citizens may be inclined to stay home unless they receive a specific inducement to participate.

At the same time, we are convinced that many of the context conditions of our case are by no means unique. The emergence of challenger parties, often with a populist element, is a key feature of recent party system transformation in Western Europe (De Vries and Hobolt 2020). With its strong anti-establishment and anti-corruption discourse, its conception of the elite as a separate 'caste', the importance of its charismatic leader, its 'Internet-prone internal structures' and its critical stance towards representative democracy, the $\mathrm{M}_{5} \mathrm{~S}$ is in many respects comparable to its twin movements at both ends of the ideological spectrum in other advanced democracies (Font, Graziano, and Tsakatika 2021; Ignazi 2021). ${ }^{24}$

Similarly, our focus on a referendum rather than an election campaign should not threaten generalizability in fundamental ways. Direct democracy is popular, and many countries across the world increasingly use one or multiple types of referendums or citizen initiatives (de Vreese 2007). The results are thus expected to apply in other referendum contexts in other countries. However, the absence of typical party cueing in the referendum context may allow for slightly larger effects than in election campaigns.

Finally, the movement's reliance on the online platform MeetUp might deserve some discussion. We do not believe that this specific online tool is in any way singular or inimitable. For example, the ActionNetwork in the U.S. is an "open platform that empowers individuals and groups to organize for progressive causes"25 and has been used by the Black Lives Matter Movement to organize local chapters not unlike the M5S. Another example is public chat groups (e.g. on Telegram or 4 chan), where online activity often sets the stage for real-world reactions among all kinds of groups across the political spectrum. In addition, well-known social media sites like Facebook continue to serve as public mobilization platforms for political parties and movements (e.g. Pegida in Germany). Last but not least, Donald Trump's heavy reliance on social media with its often immediate repercussions when supporters took to the streets in response to his Tweets is another evident example. Independent

\footnotetext{
${ }^{24}$ The movement's ideological position seems to escape the traditional left-right dimension, which makes its placement on a programmatic scale notoriously difficult. This feature should not affect generalizability, as our outcome of interest was not a typical left-right issue.

${ }^{25}$ Self-description on actionnetwork.org/about
} 
of the specific platform used, online mobilization that turns into political activity in the real world appears as a common feature of contemporary democracy.

While the M5S can be seen as a prolific pioneer in exploiting an online-offline campaigning tandem, its successful application is not confined to Italy. One key take-away of this article is that traditional grassroots mobilization efforts continue to matter even in the digital age - specifically if they are organized around local grievances under a strong umbrella organization. As the internet gives way to ever more professionalized, personalized, decentralized campaigns, our findings suggest that a combination of the online and the offline sphere might represent a winning strategy for modern political movements and challenger parties. Perhaps the most important implication of our finding is that real grassroots movements can successfully overcome the apparent trade-off between high-impact activities and geographic reach (Handan-Nader et al. 2021). Their campaigns are characterized by decentralization and place-based political appeals resulting in unusually effective political mobilization within natural social networks and communities. Importantly, this highly effective mode of political mobilization does not come at the cost of limited spatial "scalability", exactly because these movements do not depend on central top-down coordination. As such, the grassroots movements of our time are likely to remain a major source shaping - and sometimes changing - the course of contemporary political contestation by successfully combining online coordination of local activists with more traditional political mobilization on the ground.

\section{References}

André, Audrey, and Sam Depauw. 2016. "The electoral impact of grassroots activity in the 2012 local elections in Flanders." Acta Politica 51 (2): 131-152.

Barreto, Matt A., and Stephen A. Nuño. 2011. "The Effectiveness of Coethnic Contact on Latino Political Recruitment." Political Research Quarterly 64 (2): 448-459.

Bordignon, Fabio, and Luigi Ceccarini. 2013. "Five Stars and a Cricket. Beppe Grillo Shakes Italian Politics." South European Society and Politics 18 (4): 427-449.

Campante, Filipe, Ruben Durante, and Francesco Sobbrio. 2018. "Politics 2.0: The Multifaceted Effect of Broadband Internet on Political Participation." Journal of the European Economic Association 16 (4): 1094-1136.

Ceccarini, Luigi, and Fabio Bordignon. 2017. "Referendum on Renzi: The 2016 Vote on the Italian Constitutional Revision." South European Society and Politics 22 (3): 281-302. 
de Vreese, Claes H. 2007. The Dynamics of Referendum Campaigns: An International Perspective. Springer. Google-Books-ID: wHuGDAAAQBAJ.

De Vries, Catherine E, and Sara B Hobolt. 2020. Political entrepreneurs: The rise of challenger parties in Europe. Princeton University Press.

De Vries, Catherine E., Sara B. Hobolt, and Stefanie Walter. 2021. "Politicizing International Cooperation: The Mass Public, Political Entrepreneurs, and Political Opportunity Structures." International Organization 75 (2): 306-332. Publisher: Cambridge University Press.

Doherty, David, Conor M. Dowling, Alan S. Gerber, and Gregory A. Huber. 2017. "Are Voting Norms Conditional? How Electoral Context and Peer Behavior Shape the Social Returns to Voting." The Journal of Politics 79 (3): 1095-1100.

Ellinas, Antonis A, and lasonas Lamprianou. 2019. "Far Right Activism and Electoral Outcomes." Party Politics 25 (3): 448-460.

Enos, Ryan D., and Eitan D. Hersh. 2015. "Party Activists as Campaign Advertisers: The Ground Campaign as a Principal-Agent Problem." American Political Science Review 109 (2): 252-278.

Font, Nuria, Paolo Graziano, and Myrto Tsakatika. 2021. "Varieties of Inclusionary Populism? SYRIZA, Podemos and the Five Star Movement." Government and Opposition 56 (1): 163-183. Publisher: Cambridge University Press.

Foos, Florian, and Eline A De Rooij. 2017. "All in the Family: Partisan Disagreement and Electoral Mobilization in Intimate Networks - a Spillover Experiment." American Journal of Political Science 61 (2): 289-304.

Foos, Florian, and Peter John. 2018. "Parties are no civic charities: Voter contact and the changing partisan composition of the electorate." Political Science Research and Methods 6 (2): 283-298.

Gerber, Alan S., and Donald P. Green. 2000. "The Effects of Canvassing, Telephone Calls, and Direct Mail on Voter Turnout: A Field Experiment." American Political Science Review 94 (3): 653-663.

Green, Donald P., and Alan S. Gerber. 2016. “Voter Mobilization, Experimentation, and Translational Social Science." Perspectives on Politics 14 (3): 738-749.

Green, Donald P., and Alan S. Gerber. 2019. Get Out the Vote: How to Increase Voter Turnout. 4th edition ed. Brookings Institution Press.

Grillo, Beppe. 2005. “Incontriamoci: MeetUp I Il Blog di Beppe Grillo.”.

Hainmueller, Jens. 2012. "Entropy balancing for causal effects: A multivariate reweighting method to produce balanced samples in observational studies." Political Analysis 20 (1): 25-46. 
Handan-Nader, Cassandra, Daniel E. Ho, Alison Morantz, and Tom A. Rutter. 2021. "The Effectiveness of a Neighbor-to-Neighbor Get-Out-the-Vote Program: Evidence from the 2017 Virginia State Elections." Journal of Experimental Political Science 8 (2): 145-160.

Huckfeldt, R. Robert. 1979. "Political Participation and the Neighborhood Social Context." American Journal of Political Science 23 (3): 579-592.

Huckfeldt, Robert, and John Sprague. 1992. "Political Parties and Electoral Mobilization." American Political Science Review 86 (1): 70-86.

Ignazi, Piero. 2021. "The failure of mainstream parties and the impact of new challenger parties in France, Italy and Spain." Italian Political Science Review/Rivista Italiana di Scienza Politica 51 (1): $100-116$.

Jacobson, Gary C. 2015. “How Do Campaigns Matter?" Annual Review of Political Science 18 (1): 31-47.

Kalla, Joshua L., and David E. Broockman. 2018. "The Minimal Persuasive Effects of Campaign Contact in General Elections: Evidence from 49 Field Experiments." American Political Science Review 112 (1): 148-166.

Kitschelt, Herbert P. 1994. The Transformation of European Social Democracy. Cambridge, UK: Cambridge University Press.

Kriesi, Hanspeter. 2014. “The Populist Challenge.” West European Politics 37 (2): 361-378.

Lazarsfeld, Paul F., Bernhard Berelson, and Hazel Gaudet. 1948. The People's Choice: How the Voter Makes up His Mind in a Presidential Campaign. New York: Columbia University Press.

LeDuc, Lawrence. 2003. "Referendums and Elections: How Do Campaigns Differ?" In Do Political Campaigns Matter?: Campaign Effects in Elections and Referendums, ed. David M. Farrell, and Rüdiger Schmitt-Beck. Routledge.

Mair, Peter. 2009. "Representative versus Responsible Government.".

Mosca, Lorenzo, and Filippo Tronconi. 2019. "Beyond left and right: the eclectic populism of the Five Star Movement." West European Politics 42 (6): 1258-1283. Publisher: Routledge _eprint: https://doi.org/10.1080/01402382.2019.1596691.

Nickerson, David W. 2008. "Is Voting Contagious? Evidence From Two Field Experiments." American political Science Review pp. 49-57.

Panebianco, Angelo. 1988. Political Parties: Organization and Power. Cambridge: Cambridge University Press.

Pasquino, Gianfranco, and Marco Valbruzzi. 2017. "Italy Says No: The 2016 Constitutional Referendum and Its Consequences." Journal of Modern Italian Studies 22 (2): 145-162. 
Pons, Vincent. 2018. "Will a Five-Minute Discussion Change Your Mind? A Countrywide Experiment on Voter Choice in France." American Economic Review 108 (6): 1322-1363.

Putnam, Robert D. 2000. Bowling alone: The collapse and revival of American community. Simon and schuster.

Schaub, Max, and Davide Morisi. 2020. "Voter Mobilisation in the Echo Chamber: Broadband Internet and the Rise of Populism in Europe." European Journal of Political Research p. (forthcoming).

Schumacher, Gijs, Catherine E. de Vries, and Barbara Vis. 2013. “Why Do Parties Change Position? Party Organization and Environmental Incentives." Journal of Politics 75 (02): 464-477.

Sinclair, Betsy. 2012. The Social Citizen: Peer Networks and Political Behavior. University of Chicago Press.

Sinclair, Betsy, Margaret McConnell, and Melissa R. Michelson. 2013. "Local Canvassing: The Efficacy of Grassroots Voter Mobilization." Political Communication 30 (1): 42-57.

Whiteley, Paul F., and Patrick Seyd. 1994. "Local Party Campaigning and Electoral Mobilization in Britain." The Journal of Politics 56 (1): 242-252. 


\section{A Appendix:}

\section{Place-Based Campaigning: The Political Impact of Real Grassroots Mobilization}

\section{Contents}

A.1 M5S groups on MeetUp ........................... A2

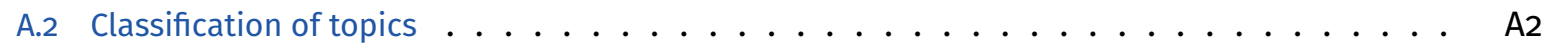

A.3 Classification of events . . . . . . . . . . . . . . . . . . . . . A3

A.4 Robustness: municipality level . . . . . . . . . . . . . . . . . . . . A4

A.4.1 Unweighted results (events instead of participants) . . . . . . . . . . . . A4

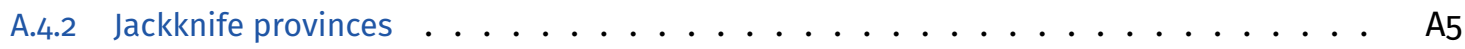

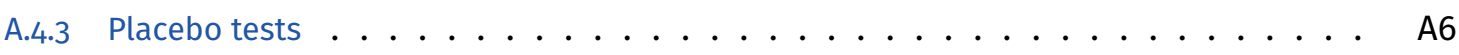

A.4.4 Varying campaign period . . . . . . . . . . . . . . . . A7

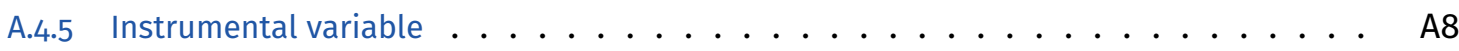

A.5 Robustness: individual level . . . . . . . . . . . . . . . . . . . . . . . A14

A.5.1 Unweighted results (events instead of participants) . . . . . . . . . . . . A14

A.6 Mechanisms ........................... A16

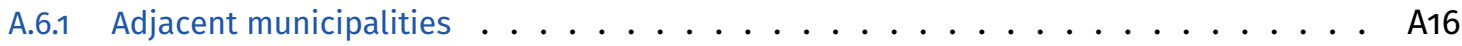

A.6.2 Activation of in-partisans ..................... . A18

A.6.3 Mobilization of inactive voters . . . . . . . . . . . . . . A19

A.7 Indoor vs. outdoor events . . . . . . . . . . . . . . . . . . A19

A.8 summary statistics . . . . . . . . . . . . . . . . . . . . . . A21 


\section{A.1 M5S groups on MeetUp}

We applied the following multi-step procedure to arrive at the universe of M5S groups on MeetUp.

1. Collect all MeetUp groups that self-selected into the top-level categories "Amici di Beppe Grillo" ( $\mathrm{N}=$ 129) or "Movimento 5 Stelle" ( $\mathrm{N}=961)$.

2. Full-text search in MeetUp. Keywords: "movimento 5 stelle" ( $N=1124)$ and "beppe grillo" $(\mathrm{N}=500)$

3. Delete duplicates resulting from dual approach (resulting $\mathrm{N}=1177$ )

4. Drop false positives that do not have any of the keywords in either their URL, group name or group description: "m5s", "movimento", "stelle", "grilli", "grillo" or "attivisti". For example, these are groups concerned with local politics without explicit reference to M5S but still using the tag "Movimento 5 Stelle" to attract members. We exclude these groups, in total 30 . (resulting $N=1147$ )

5. For the presented analysis, we also exclude all true positives that operate outside of Italy. (resulting $\mathrm{N}$ $=1044$ )

\section{A.2 Classification of topics}

Table A.1: Grouping of 300 topfeatures (excl. generic terms not removed by pre-processing)

\begin{tabular}{|c|c|c|}
\hline topic & terms & $\begin{array}{l}\text { total } \mathrm{nr} \\
\text { of } \\
\text { terms }\end{array}$ \\
\hline localpolitics & comunale, comune, consiglio, locale, regionale, territorio & 74707 \\
\hline mobilization & $\begin{array}{l}\text { appuntamento, attivisti, attivita, banchetti, banchetto, centro, citta, } \\
\text { gazebo, manifestazione, numerosi, piazza, portavoce, sala, sede }\end{array}$ & 67580 \\
\hline meeting & evento, incontro, riunione & 58726 \\
\hline m5s & 5_stelle, beppe_grillo, m5s, movimento, movimento_5_stelle & 50061 \\
\hline community & $\begin{array}{l}\text { amici, associazione, comitato, conoscere, coordinamento, gruppi, } \\
\text { gruppo, insieme, organizzazione, pubblica, rete }\end{array}$ & 44494 \\
\hline populism & cittadini, no, politica & 36126 \\
\hline directdemocracy & $\begin{array}{l}\text { campagna, costituzionale, costituzione, firme, iniziative, lista, } \\
\text { mozione, partecipare, partecipazione, proposta, proposte, } \\
\text { referendum }\end{array}$ & 31696 \\
\hline economy & lavori, lavoro & 17618 \\
\hline deliberation & $\begin{array}{l}\text { aggiornamento, argomenti, discussione, futuro, idee, informazione, } \\
\text { portare, presentazione, sapere, seduta }\end{array}$ & 17252 \\
\hline institutions & commissione, italia, legge, nazionale, presidente & 13355 \\
\hline elections & candidati, elettorale, elezioni & 10419 \\
\hline environment & acqua, ambiente, rifiuti, terra & 7621 \\
\hline europe & euro & 1730 \\
\hline
\end{tabular}


Figure A.1: Relevance of Referendum within Direct Democracy Feature

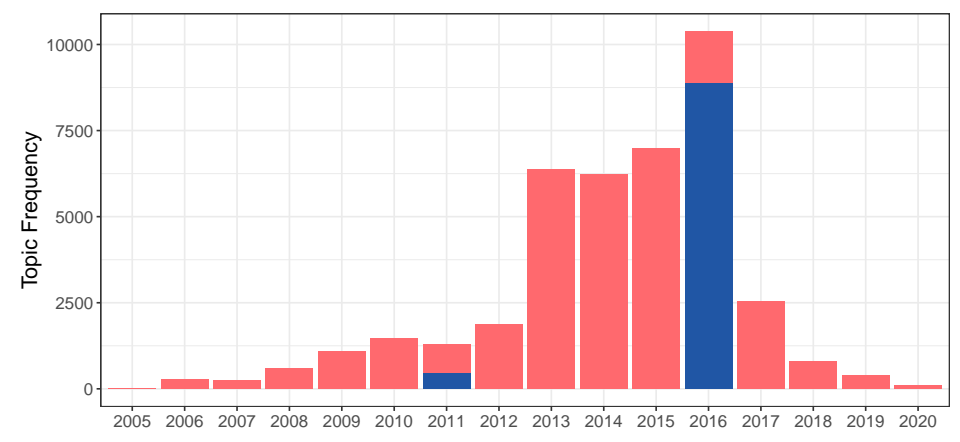

general: direct democracy features

specific: referendum | costituzione | costituzionale

\section{A.3 Classification of events}

Table A.2: List of Strings to Classify Events

\begin{tabular}{|c|c|c|}
\hline location & strings & N (\%) \\
\hline outdoor & $\begin{array}{l}\text { "parco", "parcheggio", "p.za", "p.zza ", "pzza", "piazza", "piazzetta", "piazzale", "piazze", } \\
\text { "centro", "in centro", "giardini", "giardinetti", "spazio", "centro storico", "rotonda", "punto } \\
\text { informativo", "luogo di incontro", "punto di incontro", "infopoint", "info point", "meeting } \\
\text { point", "meetingpoint", "pubblico", "lungolago", "lungomare", "porta di mare", "lido", } \\
\text { "bagni", "bagno", "porto", "marina", "marinai", "passeggiata", "statua", "bosco", "arco", } \\
\text { "archi", "portico", "portici", "piazetta", "centro commerciale", "zona", "zona pedonale", } \\
\text { "marciapiede", "area", "mercato", "mercatino", "galleria", "gazebo", "5 stelle", "torre", } \\
\text { "corso", "angolo", "stazione", "fermata", "ingresso", "difronte", "fronte", "davanti", } \\
\text { "vicino", "presso le", "presso il", "presso la", "sotto le", "sotto la", "sotto il" }\end{array}$ & $32 ' 881$ (15.3) \\
\hline indoor & 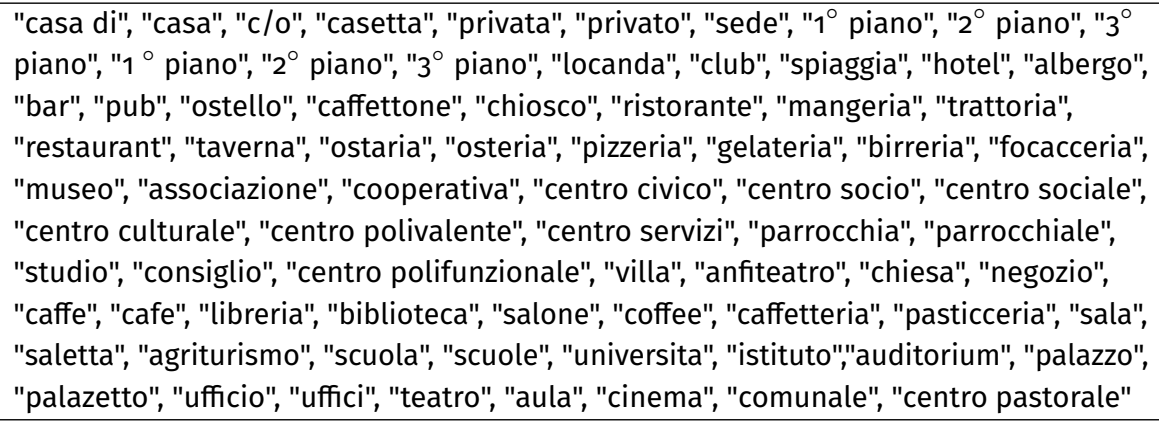 & $67^{\prime} 837(31.6)$ \\
\hline \multirow[t]{2}{*}{$\begin{array}{l}\text { un- } \\
\text { known }\end{array}$} & & $113^{\prime} 870(52.5)$ \\
\hline & & $214 ' 588$ (100) \\
\hline
\end{tabular}




\section{A.4 Robustness: municipality level}

\section{A.4.1 Unweighted results (events instead of participants)}

Table A.3: OLS estimates (municipality), does M5S grassroots mobilization (events only) predict referendum No-vote share?

\begin{tabular}{|c|c|c|c|c|}
\hline & \multicolumn{4}{|c|}{$\%$ No in referendum } \\
\hline & (1) & (2) & (3) & (4) \\
\hline M5S activity (cont., unweighted) & $\begin{array}{c}1.59 \\
(0.71)\end{array}$ & $\begin{array}{c}0.52 \\
(0.22)\end{array}$ & $\begin{array}{c}0.28 \\
(0.12)\end{array}$ & $\begin{array}{c}0.32 \\
(0.16)\end{array}$ \\
\hline \multicolumn{2}{|l|}{ M5S vote share 2013 (\%) } & \multicolumn{3}{|c|}{$\begin{array}{c}0.25 \\
(0.05)\end{array}$} \\
\hline Constant & $\begin{array}{c}59.37 \\
\text { (o.66) }\end{array}$ & $\begin{array}{l}59.47 \\
(0.02)\end{array}$ & $\begin{array}{l}76.29 \\
(2.06)\end{array}$ & $\begin{array}{l}61.41 \\
(0.10)\end{array}$ \\
\hline \multicolumn{2}{|l|}{ Province FE } & $\checkmark$ & $\checkmark$ & $\sqrt{ }$ \\
\hline \multicolumn{2}{|l|}{ Controls } & \multicolumn{3}{|c|}{$\checkmark$} \\
\hline \multicolumn{4}{|l|}{ Entropy balanced } & $\frac{\sqrt{ }}{780-\overline{4}}$ \\
\hline Provinces & 110 & 110 & 110 & 110 \\
\hline $\operatorname{adj} . R^{2}$ & 0.00 & 0.55 & 0.71 & 0.72 \\
\hline $\operatorname{adj} . R^{2}$ (within) & 0.00 & 0.00 & 0.34 & 0.00 \\
\hline RMSE & 8.73 & 5.86 & 4.69 & 4.71 \\
\hline \multicolumn{5}{|c|}{$\begin{array}{l}\text { Note: Clustered standard errors by province in parentheses. Con- } \\
\text { trols omitted from table: PD: \% votes } 2013, \% \text { turnout } 2013 \text {, income } \\
\text { per cap, } \% \text { unemployed, } \% \text { university degree, \% low education, } \% \\
\text { foreigners, population density. Same variables used for matching, } \\
\text { history omitted from matching. }\end{array}$} \\
\hline
\end{tabular}




\section{A.4.2 Jackknife provinces}

Given that M5S mobilization is less common in more rural and smaller provinces the immediate question is if and how the M5S effects vary across areas which are more or less urbanized. To address this concern we control for population density in all our models. Yet, it might still be the case that our findings are driven by particular provinces or regions. For instance, entire provinces might be more or less urbanized and still vary on several other factors. To further address this concern, we drop each province from our estimation and re-estimate our models.

Figure A.2 estimates such a jackknife test and reports each iterations of the process. Each coefficient represents a model in which one province out of total 110 provinces is dropped. The results are reassuring. Not not only is the pooled jackknife test significant but each iteration of the test returns positive and significant coefficients, which are very similar in size to the estimates we report in the main body of the text.

Figure A.2: Jackknifing municipalities by province

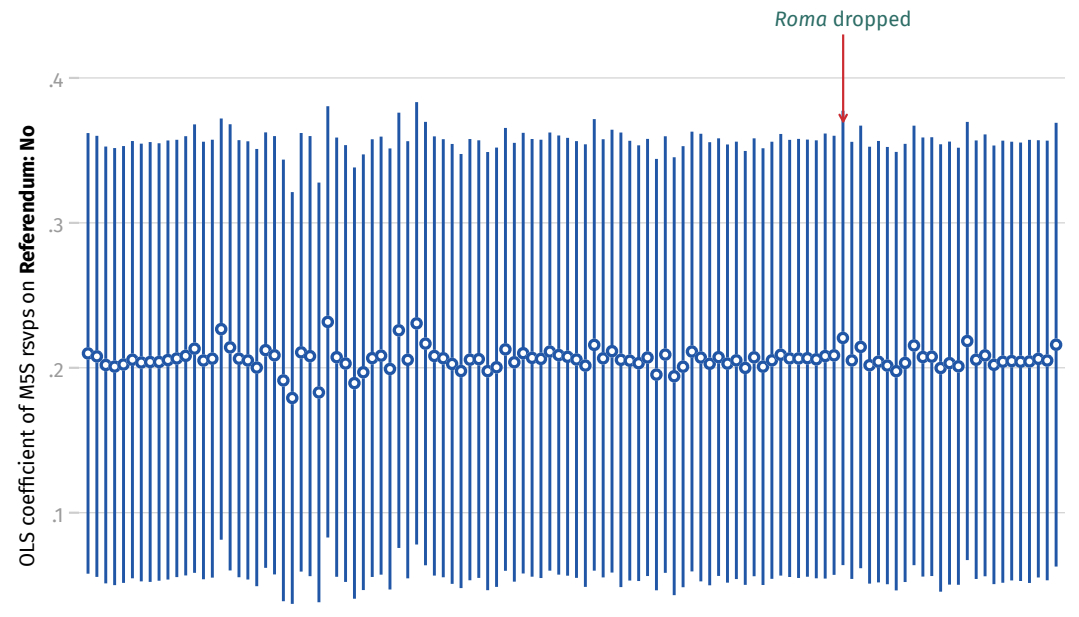

jackknife: province (1-110) 


\section{A.4.3 Placebo tests}

Our matching approach is based upon the idea that we observe all key characteristics driving M5S mobilization. However, some unobserved factors like local norms or specific traditions of political contestation might drive both local M5S activity and opposition to the referendum (common cause). One way to shed some light on these methodologically challenging problems are placebo models. Since we have rich information also about M5S mobilization after the 2016 referendum, we can use this information to estimate whether future M5S mobilization affects the past 2016 referendum results. The idea behind this placebo test is that we should not expect any effects of future mobilization on past political results - specifically for municipalities that have not yet experienced any M5S mobilization. If this was the case we would have strong reasons to assume that other factors than M5S grassroots activity drive our findings.

Figure A.3: Placebo effect of M5S events on No-vote share

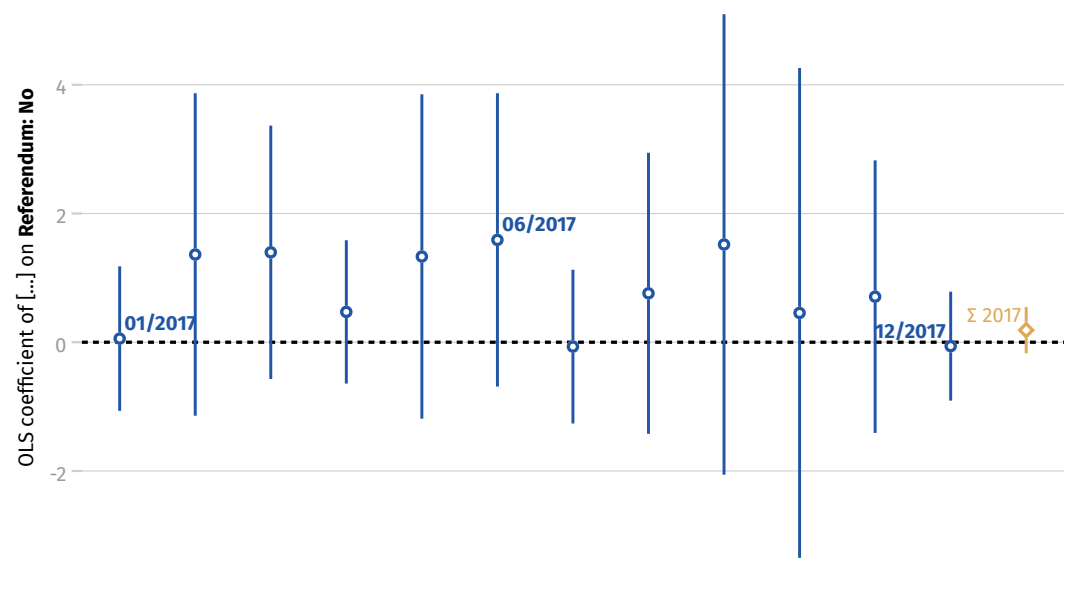

To conduct these tests we collected all events organized by M5S in the year after the 2016 referendum. We then placed these events into the referendum period, and re-estimated our models for all municipalities which had not experienced any M5S events during the referendum campaign. Figure A.3 reports the findings from these models. Each coefficient stands for a one month period after the referendum; while the last coefficient shows the pooled effect for all events taking place in the year 2017. Coefficients are surrounded by $95 \%$ confidence intervals. In total 107 "new" municipalities experience M5S events. As expected, local M5S activity in 2017 is not predictive of the 2016 No-vote share, which in turn lends credence to a causal interpretation of our positive and significant main effect. 


\section{A.4.4 Varying campaign period}

One reviewer raised concerns in relation to the time period we used to define the campaign period for the referendum. They outlined that the actual campaign period was much shorter and, thus, we should adapt it accordingly. We read this as a call for a robustness test: if anything our approach to use a somewhat longer period is a more conservative approach, i.e. it captures more events which are theoretically implausible to affect the outcome we study.

To address their concern we re-defined the campaign period along the time frame provided by the reviewer: the end of September until December 2016. We then re-estimated the main models from Table 1 in our paper for the municipality-level analyses only - as the analyses of the individual-level panel data remains valid according to the reviewer's definition. In Table A.4 we report the replication of our main analyses using the period outlined by the reviewer to study the effect of mobilization on the referendum Nos.

Table A.4: OLS estimates (municipality), different campaign period used to measure M5S mobilization

\begin{tabular}{|c|c|c|c|c|c|c|c|c|}
\hline & \multicolumn{8}{|c|}{$\%$ No in referendum } \\
\hline & \multicolumn{4}{|c|}{ Binary } & \multicolumn{4}{|c|}{ Continuous } \\
\hline & (1) & (2) & (3) & (4) & (5) & (6) & (7) & (8) \\
\hline M5S activity $(0,1)$ & $\begin{array}{l}2.52 \\
(1.17)\end{array}$ & $\begin{array}{c}0.92 \\
(0.36)\end{array}$ & $\begin{array}{c}0.70 \\
(0.19)\end{array}$ & $\begin{array}{c}0.48 \\
(0.21)\end{array}$ & & & & \\
\hline M5S activity (cont.) & & & & & $\begin{array}{c}1.58 \\
(0.59)\end{array}$ & $\begin{array}{c}0.50 \\
(0.18)\end{array}$ & $\begin{array}{l}0.30 \\
(0.11)\end{array}$ & $\begin{array}{c}0.31 \\
(0.13)\end{array}$ \\
\hline M5S: \% votes 2013 & & & $\begin{array}{c}0.25 \\
(0.05)\end{array}$ & & & & $\begin{array}{c}0.25 \\
(0.05)\end{array}$ & \\
\hline Constant & $\begin{array}{l}59.35 \\
(0.66)\end{array}$ & $\begin{array}{l}59.46 \\
(0.02)\end{array}$ & $\begin{array}{l}76.22 \\
(2.06)\end{array}$ & $\begin{array}{c}61.41 \\
(0.10)\end{array}$ & $\begin{array}{l}59.35 \\
(0.66)\end{array}$ & $\begin{array}{l}59.47 \\
(0.02)\end{array}$ & $\begin{array}{l}76.26 \\
(2.06)\end{array}$ & $\begin{array}{l}61.41 \\
\text { (o.10) }\end{array}$ \\
\hline Province FE & & $\checkmark$ & $\checkmark$ & $\checkmark$ & & $\checkmark$ & $\checkmark$ & $\checkmark$ \\
\hline Controls & & & $\checkmark$ & & & & $\checkmark$ & \\
\hline Entropy balanced & & & & $\checkmark$ & & & & $\checkmark$ \\
\hline$\overline{\mathrm{O}} \overline{\mathrm{bs}}--\cdots$ & $\overline{7994}$ & $\overline{7} 994^{-}$ & $\overline{7} \overline{80} \overline{4}$ & $\overline{78} \overline{\mathrm{C}}$ & $7 \overline{994}$ & 7994 & $\overline{7} 8 \overline{0} \overline{4}$ & 7804 \\
\hline Provinces & 110 & 110 & 110 & 110 & 110 & 110 & 110 & 110 \\
\hline $\operatorname{adj} . R^{2}$ & 0.01 & 0.55 & 0.71 & 0.73 & 0.01 & 0.55 & 0.71 & 0.73 \\
\hline adj. $R^{2}$ (within) & 0.01 & 0.00 & 0.34 & 0.00 & 0.01 & 0.00 & 0.34 & 0.00 \\
\hline RMSE & 8.72 & 5.86 & 4.69 & 4.64 & 8.72 & 5.86 & 4.69 & 4.64 \\
\hline
\end{tabular}

It becomes evident that this coding decision does not affect our findings. The new definition still reports a significant effect of M5S mobilization on No voters in the referendum. Interestingly the effects are somewhat stronger than the effects we report in the main body of the text. This could be understood as support for the idea, that the coding we use in the main body of the text relies on a somewhat more conservative approach also covering events not related to mobilization about the referendum. 


\section{A.4.5 Instrumental variable}

Our instrumental variable approach leverages the fact that M5S mobilization was predominantly coordinated online. As discussed, Beppe Grillo actively called upon his supporters to use the web in general and the Meetup platform in particular, as a tool of collective organization. Thus, access to the internet became a necessary condition to be informed about and able to participate in M5S events. From today's perspective this might appear as a negligible impediment but it certainly was a considerable issue when M5S started mobilizing from 2005 onwards. According to official data from the OECD and the Italian communication ministry, only about every third Italian household had access to broadband internet at the time and although mobile internet had already existed it was far from being commercialized.

Even in 2009 , the year M5S started to break through, this share had risen to only about $50 \%$ as reported in Figure A.4.

Figure A.4: Internet penetration in Italy, 2007-2019

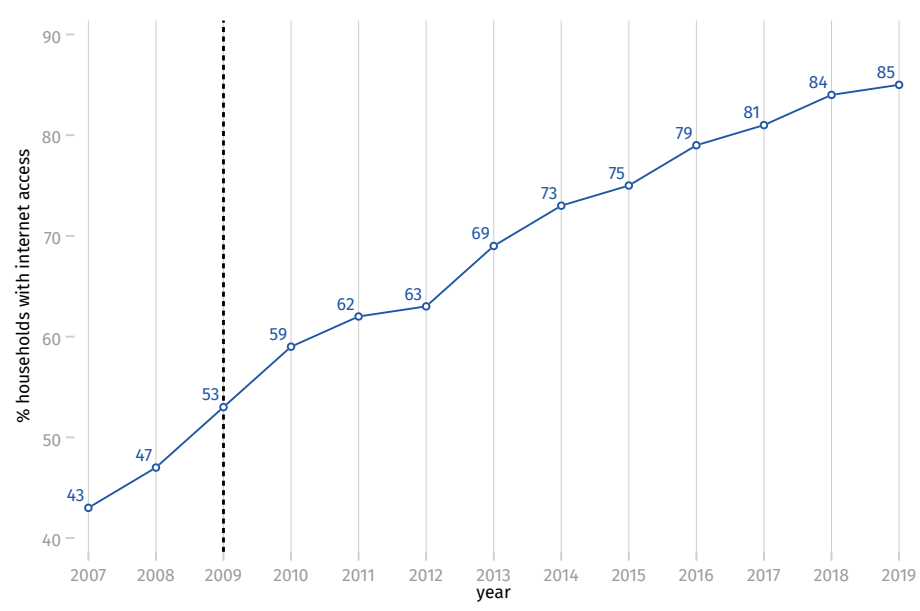

Important for our purpose, broadband access is to a certain extent quasi-randomly assigned in Italy Campante, Durante, and Sobbrio (2018); Schaub and Morisi (2020). Internet access has been provided via ADSL technology, which has been introduced in 1999 by the operator along with the telecommunication ministry. ADSL is usually provided via copper telephone wires; which means that access to it depends heavily on a household's geographical position in the pre-existing telecommunication infrastructure of a given country. Two components of the pre-existing telecommunication infrastructure determine ADSL access for end users: (a) geographical distance between the end user and the closest communication exchange (CE), and (b) geographical distance between the end user and the closest urban group stage (UGS, the technical term being "higher-order telecommunication exchange"). While the first has been unproblematic for most Italian households, distance to UGS has strongly determined ADSL access.

Indeed, in Figure A.5 we report the correlation between broadband internet access and UGS distance. The larger the distance to the closest urban group stage, the smaller the percentage of the population with broadband internet access. This relationship weakens over time: The correlation decreases over the years for which we have data on broadband internet access. All of this means that, especially during its infancy, M5S success of mobilization was clearly dependent on (hampered by) potential supporters' (lack of) access to the internet. 
Figure A.5: OLS estimates, how broadband access in Italy depends on distance to UGS, (2012-2015, 2018)

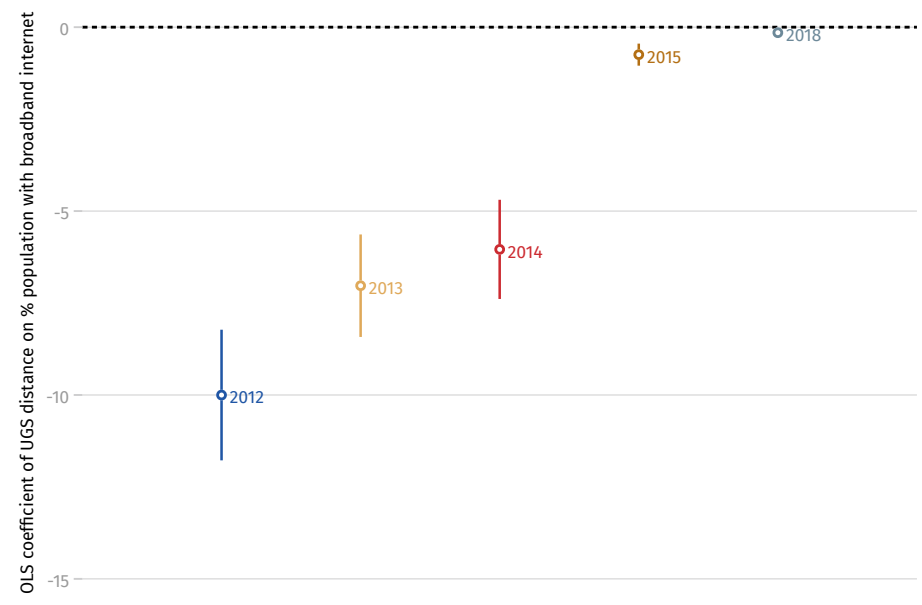

Note: Reported are OLS coefficients surrounded by $95 \%$ whiskers. All models use province fixed effects, standard errors clustered by province. ADSL information until 2015 stems from Schaub and Morisi Schaub and Morisi (2020); we web-scraped the 2018 data ourselves. 2012-2015 report \% households with adsl broadband access, 2018 report access to "next generation" internet (30 Mbit/s).

Distance to the closest UGS can thus be considered a good proxy for the investment required to connect a municipality to ADSL and hence a source of variation for the availability of high-speed internet. The map in Figure A.7a reports the geographical distance for each municipality to the next UGS in kilometers.

Figure A.6: Map of UGS distance and 2016 referendum Nos

(a) UGS distance of Italian municipalities

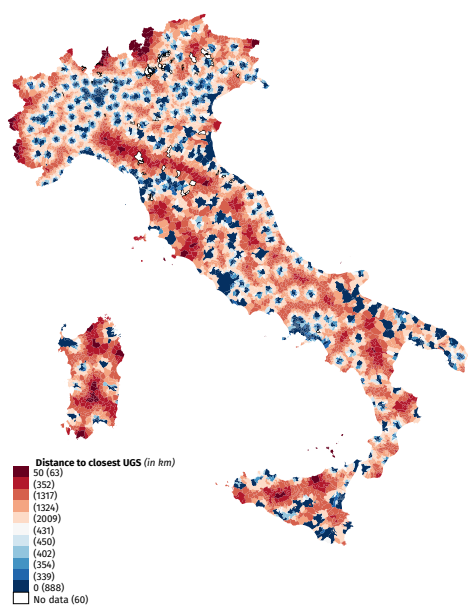

(b) Map of referendum No-vote share

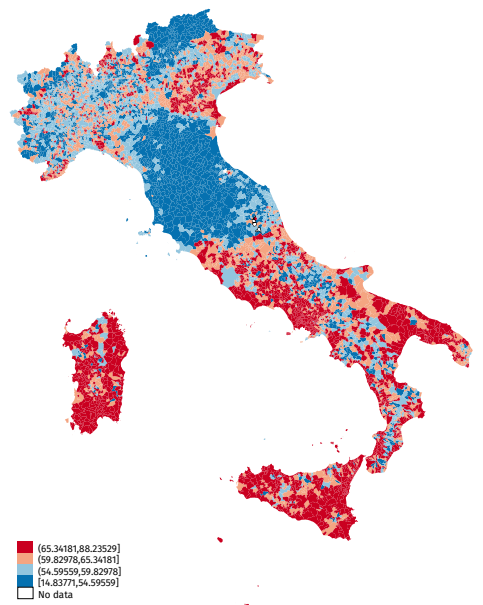

There is large variation across Italy in terms of distance to the next UGS at the time ADSL was introduced. As a consequence, this resulted in some municipalities having a higher probability to get broadband internet access at the time M5S started to mobilize than others.

The dependence on proximity to a pre-existing UGS adds quasi-random variation to the availability of fast internet. We leverage this fact in an instrumental variable design akin to previous research exploiting historical roots of TV consumption (e.g. Kearney and Levine 2015). More specifically, we use the rich information 
we gathered for each M5S group to estimate the first day a M5S group came into existence in each Italian municipality. This variable is predictive of M5S mobilization during the 2016 referendum campaign; meaning that M5S groups, which came into existence earlier, are more likely to mobilize more successfully today - even though the original topics and intentions of M5S's early days are no longer relevant for most groups we study during the referendum. We then interact this historical information with the distance of each municipality to the UGS. The intuition behind this interaction is that the timing when M5S first mobilized in a given municipality is to some extent contingent on the amount of broadband internet access provided in a given municipality. ${ }^{26}$

More formally we estimate a two-stage instrumental variable model based on our municipality-level cross-sectional data of the following form:

$$
\begin{gathered}
y_{m}=\gamma \widehat{\mathrm{MSS}_{m}}+\beta \text { population in } 2001_{m}+\alpha_{p}+\epsilon_{m} \\
\widehat{\mathrm{MSS}_{m}}=\psi \mathrm{M} 5 \mathrm{~S} \text { history }{ }_{m} \times \text { Distance } \mathrm{UGS}_{m}+\beta \text { population in } 2001_{m}+\alpha_{p}+\epsilon_{m^{\prime}}
\end{gathered}
$$

where subscript $m$ indicates again municipalities and $\alpha_{p}$ province fixed effects. In the first stage we introduce the interaction as outlined above M5S history $\times$ Distance UGS to predict the amount of M5S mobilization during the referendum. Since UGS assignment in the telecommunication infrastructure depends to some extent on population size at the time we control for the population size of each municipality in both stages. We refrain from using the same set of controls as outlined above since they essentially turn into post-treatment variables given the more historical perspective of our IV approach. Yet, as we outline below, our findings remain robust when introducing our set of municipality level controls.

Independence and exclusion restriction The first crucial aspect of any instrumental variable design is the independence of the instrument. Transferred to our design, a violation of independence would mean that municipalities further away from a UGS station are also different on other pre-treatment characteristics which could cause the rise and mobilization of M5S. For instance, one might argue that the Italian telecommunication structure was subject to political biases, since ministers might have tried to deliver better phone connectivity to supportive or electorally pivotal regions. This appears highly unlikely in our case. First, as outlined above, the telecommunication infrastructure was already in place long before Italian administrations thought about providing internet to its population.

Second, and more strikingly, we are able to empirically assess the validity of this assumption. We use the 1996 ITANES election study (i.e. pre-ADSL allocation) to examine if municipalities further away from UGS stations are any different with respect to relevant political factors such as voting preferences, left-right placement, populist attitudes and their support for democracy more generally. The coefficients presented in Figure A.8 show that we do not find any significant difference due to a municipality's distance to the UGS for any of the mentioned variables.

Furthermore, we use the same variables to estimate further placebo tests. In so doing, we use the

\footnotetext{
${ }^{26} \mathrm{Arguably}$, one might use both components of the interaction as stand-alone instrumental variables. However, at least with respect to the historical information, we are concerned that the exclusion restriction does not hold: even though thematically there is no clear link between the topics of the earlier organization and today's M5S groups, other common causes might drive the past organization, today's organization as well as voting ' $\mathrm{No}$ ' in the referendum - e.g. anti-government sentiment. Such concerns appear less pressing in the case of the infrastructure instrument, which is why Table A.6 below also reports results for distance to UGS separately, i.e. not interacted with the history of local M5S groups.
} 
Figure A.8: Testing independence of UGS distance, ITANES 1996

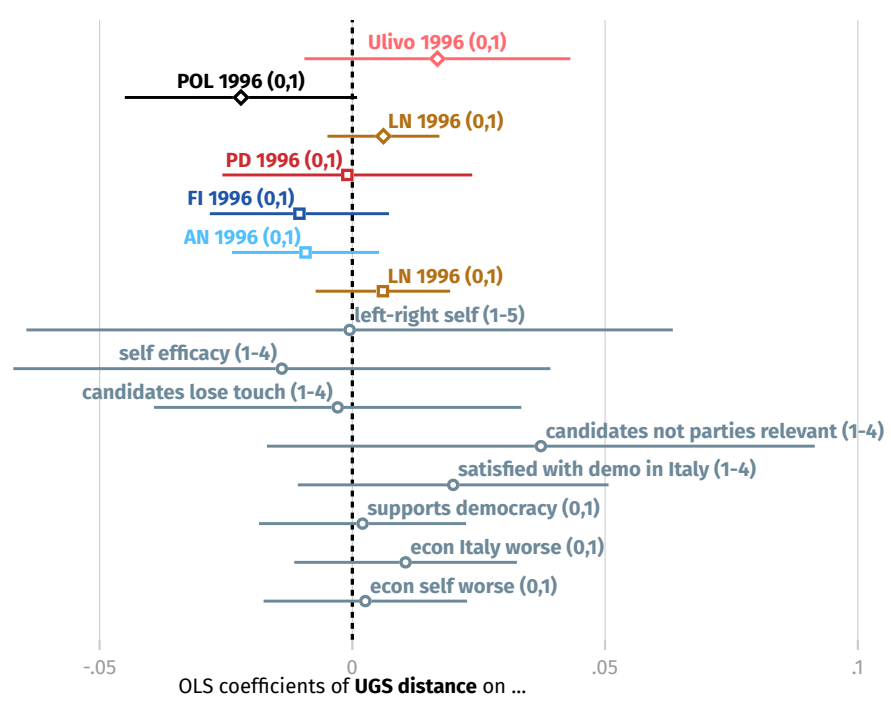

Note: The coefficient plots are point estimates from several OLS regressions surrounded by $95 \%$ confidence intervals. The first four voting estimates are list votes; the following three party votes.

instrumental variable specification discussed above and each of the variables reported in the coefficient plot as our outcomes. Table A.5 reports the findings of these placebo tests. Again, we do not find any significant effect of the instrument on any of these pre-treatment outcomes suggesting that there is no obvious reason why the independence of our instrument would be violated. Clearly, the telecommunication infrastructure was not developed independently from population size. Thus, in all instrumental variable models, we control for population size in 2001.

While we can successfully test and show the independence of our instrument, it is not possible to directly test the exclusion restriction. The exclusion restriction in our case is as follows: We have to believe that municipalities closer to an UGS station in 2001 show more M5S mobilization during the referendum only because broadband internet was available at the time the local M5S chapter was started. We do not see how the exclusion restriction would be violated; we do not have reason to assume that distance to UGS stations in 2001 drives factors which then affect whether or not people will vote against the reform in 2016.

Instrumental variable results Table A.6 reports the results of our 2SLS approach. All models have a strong first stage, indicated by F-stats of 26 and above reported at the bottom of Table A.6. Conventionally, a F-stat of 10 or more is the threshold employed to differentiate a weak from a strong instrument. This confirms the validity of our instrumental variable approach.

With regard to the estimates, the first column again reports the most conservative finding from the municipality-level analysis to ease up comparison to the IV specifications. The following three models report different specifications of the interactive instrument discussed above; the last three columns rely only on distance to the UGS as a direct instrument (without interaction).

Using our instrumental variable design clearly provides further support for the key findings of our analysis. Again we find a significant and positive effect of M5S mobilization on 'No' votes in the referendum. Interestingly, using the interactive instrument, the size of this effect is quite comparable; only if we rely on distance to the 


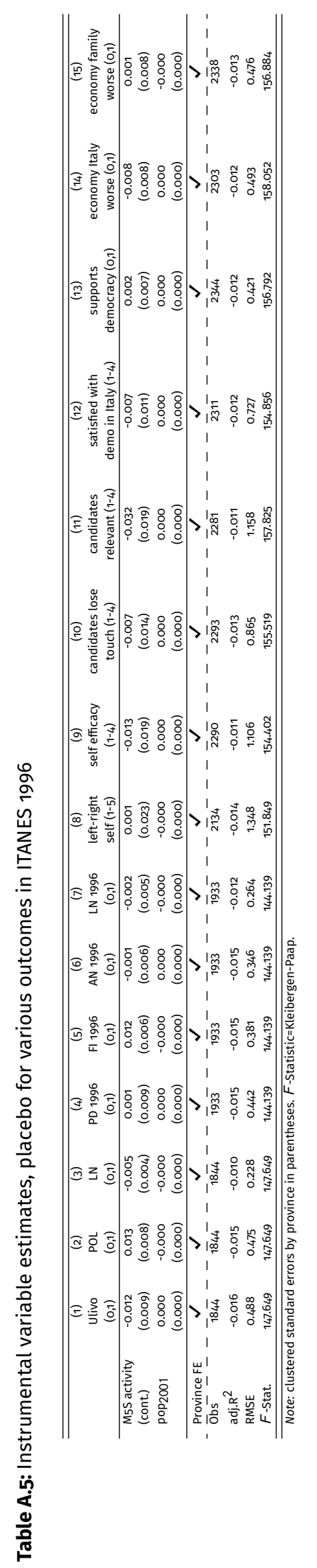


Table A.6: IV estimates (municipality), does M5S grassroots mobilization causally affect referendum results?

\begin{tabular}{|c|c|c|c|c|c|c|c|}
\hline & $\begin{array}{l}\text { OLS } \\
\text { (1) }\end{array}$ & $\begin{array}{c}\text { IV: } \\
\text { Hist } \times \text { UGS } \\
(2)\end{array}$ & $\begin{array}{c}\text { IV: } \\
\log (\text { Hist } \times \text { UGS }) \\
(3)\end{array}$ & $\begin{array}{c}\text { IV: } \\
\log (\text { Hist } \times \text { UGS }) \\
(4)\end{array}$ & $\begin{array}{l}\text { IV: } \\
\text { UGS } \\
\text { (5) }\end{array}$ & $\begin{array}{c}\text { IV: } \\
\log (\text { UGS) } \\
(6)\end{array}$ & $\begin{array}{c}\text { IV: } \\
\log (\text { UGS }) \\
(7)\end{array}$ \\
\hline M5S: activity (cont.) & $\begin{array}{c}0.21 \\
(0.08)\end{array}$ & $\begin{array}{c}0.45 \\
(0.19)\end{array}$ & $\begin{array}{c}0.45 \\
(0.17)\end{array}$ & $\begin{array}{c}0.29 \\
(0.09)\end{array}$ & $\begin{array}{l}4.33 \\
(2.10)\end{array}$ & $\begin{array}{c}2.12 \\
(1.03)\end{array}$ & $\begin{array}{c}2.34 \\
(0.75)\end{array}$ \\
\hline Constant & $\begin{array}{l}76.25 \\
(2.06) \\
\end{array}$ & & & & & & \\
\hline Province FE & $\checkmark$ & $\sqrt{ }$ & $\sqrt{ }$ & $\sqrt{ }$ & $\sqrt{ }$ & $\sqrt{ }$ & $\sqrt{ }$ \\
\hline Population 2001 & & $\checkmark$ & $\checkmark$ & & $\checkmark$ & $\checkmark$ & \\
\hline 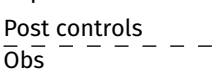 & $\overline{7804.00}-$ & $-\overline{7820.00}-$ & $--\overline{7820.00}$ & $--\frac{\checkmark}{7803.00}--$ & $-\overline{7820} . \overline{00}-$ & $-\overline{7820.00}$ & $\frac{\sqrt{ }}{-7803.00}$ \\
\hline Provinces & 110.00 & 107.00 & 107.00 & 110.00 & 107.00 & 107.00 & 110.00 \\
\hline RMSE & 4.69 & 5.86 & 5.86 & 4.66 & 6.37 & 5.96 & 4.84 \\
\hline$F$ Stat & & 144.41 & 281.67 & 286.85 & 26.40 & 76.17 & 64.38 \\
\hline
\end{tabular}

UGS as a single instrument do we find larger coefficients - as it is very common for instrumental variable models. The key reason for the stability in the size of the coefficient is that the time since the first M5S event is a strong predictor of M5S mobilization during the campaign for the 2016 referendum. 


\section{A.5 Robustness: individual level}

Figure A.9: Balance statistics individual level, raw and after entropy balancing

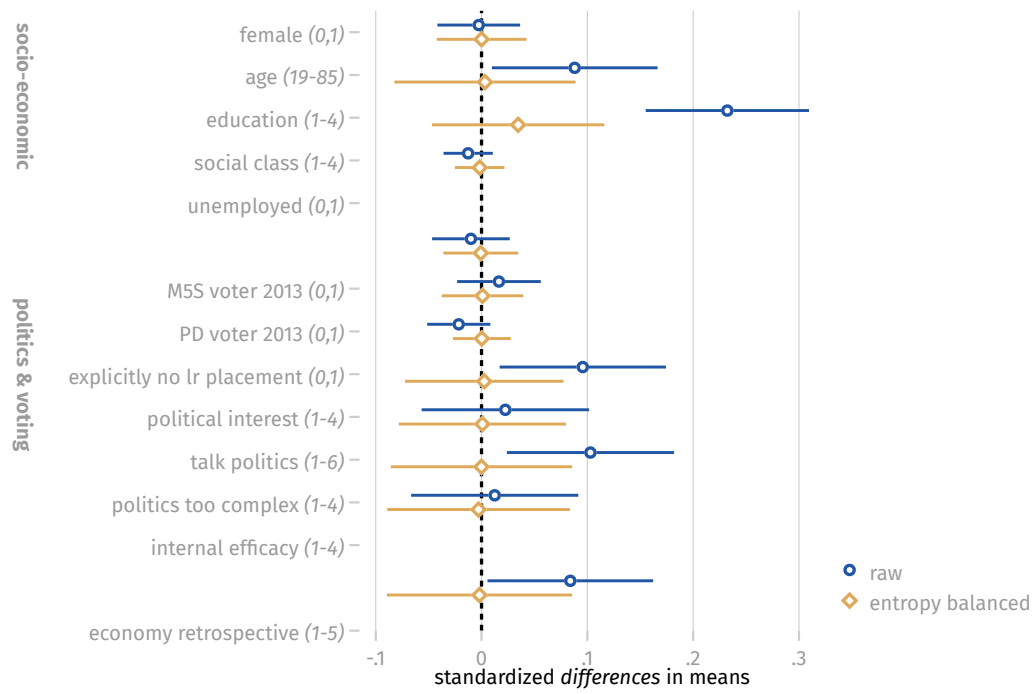

Note: Reported are OLS estimates surrounded by $95 \%$ confidence intervals. "Raw" is a model without any re-weighting, "entropy balanced" re-weights the sample according to the weights retrieved from an entropy balancing model discussed in the paper.

\section{A.5.1 Unweighted results (events instead of participants)}


Table A.7: OLS estimates (individual), does M5S grassroots mobilization (events only) predict voting 'No' in referendum?

\begin{tabular}{|c|c|c|c|c|}
\hline Vote 'No' in referendum & (1) & (2) & (3) & (4) \\
\hline M5S activity (cont., unweighted) & $\begin{array}{c}0.12 \\
(0.04)\end{array}$ & $\begin{array}{c}0.14 \\
(0.04)\end{array}$ & $\begin{array}{c}0.13 \\
(0.05)\end{array}$ & $\begin{array}{c}0.11 \\
(0.04)\end{array}$ \\
\hline M5S voter in $2013(0,1)$ & & & $\begin{array}{c}0.11 \\
(0.03)\end{array}$ & \\
\hline Constant & $\begin{array}{c}0.42 \\
(0.01)\end{array}$ & $\begin{array}{c}0.97 \\
(0.06)\end{array}$ & $\begin{array}{c}0.82 \\
(0.10)\end{array}$ & $\begin{array}{c}0.42 \\
(0.01)\end{array}$ \\
\hline Wave FE & $\checkmark$ & $\sqrt{ }$ & $\checkmark$ & $\checkmark$ \\
\hline Municipality FE & $\checkmark$ & $\checkmark$ & $\checkmark$ & \\
\hline Socio-economic controls & & $\checkmark$ & $\checkmark$ & \\
\hline Political controls & & & $\checkmark$ & \\
\hline Individual FE & & & & $\checkmark$ \\
\hline$\overline{\mathrm{O}} \overline{\mathrm{bs}}^{--------}$ & 5254 & $5206^{-}$ & $\overline{4} 0 \overline{7} 0^{-}$ & $\overline{516} \overline{6}^{-}$ \\
\hline Municipalities & 1016 & 1006 & 856 & 1012 \\
\hline $\operatorname{adj} . R^{2}$ & 0.17 & 0.25 & 0.30 & 0.51 \\
\hline adj. $R^{2}$ (within) & 0.00 & 0.09 & 0.14 & 0.00 \\
\hline RMSE & 0.45 & 0.43 & 0.42 & 0.35 \\
\hline
\end{tabular}




\section{A.6 Mechanisms}

\section{A.6.1 Adjacent municipalities}

Below we report the effects of adjacent M5S mobilization on municipalities. In Table A.8 we thereby rely on a) the full sample as in the main body of the test b) municipalities without an active M5S chapter. In the last two columns we again use the full sample but control also for the municipality's own M5S activity.

Table A.8: OLS estimates (municipality), are neighbors affected by M5S mobilization?

\begin{tabular}{|c|c|c|c|c|c|c|}
\hline & \multicolumn{2}{|c|}{ full sample (1-2) } & \multicolumn{2}{|c|}{$\begin{array}{c}\% \text { No in referendum } \\
\text { no "self-exposure" (3-4) }\end{array}$} & \multicolumn{2}{|c|}{ full sample (5-6) } \\
\hline & (1) & (2) & (3) & (4) & (5) & (6) \\
\hline M5S adjacent activity (cont.) & $\begin{array}{c}0.13 \\
(0.07)\end{array}$ & $\begin{array}{c}0.03 \\
(0.04)\end{array}$ & $\begin{array}{c}0.12 \\
(0.06)\end{array}$ & $\begin{array}{c}0.02 \\
(0.04)\end{array}$ & $\begin{array}{c}0.12 \\
(0.06)\end{array}$ & $\begin{array}{c}0.02 \\
(0.04)\end{array}$ \\
\hline M5S vote share 2013 (\%) & & $\begin{array}{c}0.24 \\
(0.05)\end{array}$ & & $\begin{array}{l}0.25 \\
(0.05)\end{array}$ & & $\begin{array}{c}0.25 \\
(0.05)\end{array}$ \\
\hline M5S activity (cont.) & & & & & $\begin{array}{l}0.34 \\
(0.12)\end{array}$ & $\begin{array}{c}0.21 \\
(0.08)\end{array}$ \\
\hline Constant & $\begin{array}{l}59.16 \\
(0.08)\end{array}$ & $\begin{array}{l}75.62 \\
(2.12)\end{array}$ & $\begin{array}{l}59.36 \\
(0.09)\end{array}$ & $\begin{array}{l}76.38 \\
(2.07)\end{array}$ & $\begin{array}{l}59.29 \\
(0.10)\end{array}$ & $\begin{array}{l}76.27 \\
(2.06)\end{array}$ \\
\hline Province FE & $\checkmark$ & $\checkmark$ & $\checkmark$ & $\checkmark$ & $\sqrt{ }$ & $\checkmark$ \\
\hline $\begin{array}{l}\text { Controls } \\
\text { Obss }----------\end{array}$ & $7370-$ & $-\frac{\sqrt{ }}{7183}-$ & $-\overline{799 \overline{4}}$ & $\frac{\sqrt{ }}{78 \overline{0} \overline{4}}--$ & $\overline{7994}$ & $-\frac{\sqrt{ }}{7804}-$ \\
\hline Provinces & 110 & 110 & 110 & 110 & 110 & 110 \\
\hline $\operatorname{adj} . R^{2}$ & 0.53 & 0.69 & 0.55 & 0.71 & 0.55 & 0.71 \\
\hline $\operatorname{adj.} R^{2}$ (within) & 0.00 & 0.33 & 0.00 & 0.34 & 0.00 & 0.34 \\
\hline RMSE & 5.95 & 4.80 & 5.86 & 4.69 & 5.86 & 4.69 \\
\hline
\end{tabular}

In Table A.9 we follow a reviewer's advice an re-estimate the same models but only for municipality which themselves had an active M5S chapter. We find again a significant effect of a municipality's own chapter and no effect of adjacent mobilization. Notice, that model 6 is no longer significant on conventional statistical levels but this is largely a power issue. 
Table A.9: OLS estimates (municipality), are active M5S municipalities affected by M5S mobilization in neighboring municipalities?

\begin{tabular}{|c|c|c|c|c|c|c|}
\hline & \multicolumn{6}{|c|}{$\%$ No in referendum } \\
\hline & (1) & (2) & (3) & (4) & (5) & (6) \\
\hline M5S adjacent activity (cont.) & $\begin{array}{c}0.56 \\
(0.33)\end{array}$ & $\begin{array}{c}0.02 \\
(0.10)\end{array}$ & $\begin{array}{c}0.02 \\
(0.15)\end{array}$ & $\begin{array}{c}0.01 \\
(0.10)\end{array}$ & $\begin{array}{c}0.51 \\
(0.33)\end{array}$ & $\begin{array}{c}0.01 \\
(0.10)\end{array}$ \\
\hline M5S: \% votes 2013 & & $\begin{array}{c}0.24 \\
(0.06)\end{array}$ & & $\begin{array}{c}0.20 \\
(0.06)\end{array}$ & & $\begin{array}{c}0.24 \\
(0.06)\end{array}$ \\
\hline M5S activity (cont.) & & & & & $\begin{array}{c}0.94 \\
(0.33)\end{array}$ & $\begin{array}{c}0.24 \\
(0.17)\end{array}$ \\
\hline Constant & $\begin{array}{l}60.41 \\
(0.94)\end{array}$ & $\begin{array}{c}94.16 \\
(5.03)\end{array}$ & $\begin{array}{l}61.80 \\
(0.40)\end{array}$ & $\begin{array}{l}88.84 \\
(4.61)\end{array}$ & $\begin{array}{l}58.37 \\
(1.34)\end{array}$ & $\begin{array}{l}93.14 \\
(5.19)\end{array}$ \\
\hline Province FE & & & $\sqrt{ }$ & $\checkmark$ & & \\
\hline Controls & & $\checkmark$ & & $\checkmark$ & & $\checkmark$ \\
\hline$\overline{\mathrm{Obs}}^{---}$ & 621 & 618 & $60 \overline{4}$ & $\overline{6} \overline{01}$ & $\overline{621}$ & 618 \\
\hline Provinces & 103 & 103 & 86 & 86 & 103 & 103 \\
\hline $\operatorname{adj} . R^{2}$ & 0.01 & 0.86 & 0.81 & 0.93 & 0.02 & 0.86 \\
\hline $\operatorname{adj} . R^{2}$ (within) & 0.01 & 0.86 & -0.00 & 0.62 & 0.02 & 0.86 \\
\hline RMSE & 9.30 & 3.51 & 4.10 & 2.53 & 9.25 & 3.50 \\
\hline
\end{tabular}




\section{A.6.2 Activation of in-partisans}

To learn about the activation effect we interact the M5S measure with the respective party-voting behavior of respondents. We here rely on the individual-level data only as it allows us to link voters directly with the mobilization in their municipalities. We rely on the same model specifications and controls as outlined in the main body of the text. This then returns the following results:

Table A.10: OLS estimates (individual), does the effect of M5S grassroots mobilization interact with previous voting? Yes.

\begin{tabular}{|c|c|c|c|c|c|c|c|c|}
\hline & \multicolumn{4}{|c|}{ Vote: No } & \multicolumn{4}{|c|}{ Turnout } \\
\hline & (1) & $(2)$ & (3) & (4) & (5) & (6) & (7) & (8) \\
\hline M5S: referendum & $\begin{array}{c}0.06 \\
(0.03)\end{array}$ & $\begin{array}{c}0.08 \\
(0.03)\end{array}$ & $\begin{array}{c}0.07 \\
(0.03)\end{array}$ & $\begin{array}{c}0.06 \\
(0.03)\end{array}$ & $\begin{array}{c}0.04 \\
(0.02)\end{array}$ & $\begin{array}{c}0.04 \\
(0.02)\end{array}$ & $\begin{array}{c}0.04 \\
(0.02)\end{array}$ & $\begin{array}{c}0.03 \\
(0.02)\end{array}$ \\
\hline M5S voter in $2013(0,1)$ & $\begin{array}{c}0.06 \\
(0.04)\end{array}$ & $\begin{array}{c}0.11 \\
(0.03)\end{array}$ & $\begin{array}{c}0.11 \\
(0.03)\end{array}$ & $\begin{array}{c}0.11 \\
(0.03)\end{array}$ & $\begin{array}{c}0.03 \\
(0.03)\end{array}$ & $\begin{array}{c}0.03 \\
(0.02)\end{array}$ & $\begin{array}{c}0.03 \\
(0.02)\end{array}$ & $\begin{array}{c}0.02 \\
(0.02)\end{array}$ \\
\hline $\begin{array}{l}\text { M5S voter in } 2013(0,1) \times \\
\text { M5S: referendum }\end{array}$ & $\begin{array}{c}0.04 \\
(0.02)\end{array}$ & & & & $\begin{array}{l}-0.00 \\
(0.02)\end{array}$ & & & \\
\hline PD voter in $2013(0,1)$ & & $\begin{array}{l}-0.07 \\
(0.04)\end{array}$ & & & & $\begin{array}{l}0.05 \\
(0.03)\end{array}$ & & \\
\hline $\begin{array}{l}\text { PD voter in } 2013(0,1) \times \\
\text { M5S: referendum }\end{array}$ & & $\begin{array}{l}-0.01 \\
(0.03)\end{array}$ & & & & $\begin{array}{l}0.00 \\
(0.02)\end{array}$ & & \\
\hline PdL voter in $2013(0,1)$ & & & $\begin{array}{c}0.15 \\
(0.06)\end{array}$ & & & & $\begin{array}{l}-0.03 \\
(0.03)\end{array}$ & \\
\hline $\begin{array}{l}\text { PdL voter in } 2013(0,1) \times \\
\text { M5S: referendum }\end{array}$ & & & $\begin{array}{l}-0.01 \\
(0.03)\end{array}$ & & & & $\begin{array}{c}0.01 \\
(0.02)\end{array}$ & \\
\hline unsure in wave 3 & & & & $\begin{array}{l}-0.26 \\
(0.03)\end{array}$ & & & & $\begin{array}{l}-0.22 \\
(0.02)\end{array}$ \\
\hline $\begin{array}{l}\text { unsure in wave } 3 \times \\
\text { M5S: referendum }\end{array}$ & & & & $\begin{array}{c}0.03 \\
(0.02)\end{array}$ & & & & $\begin{array}{l}0.00 \\
(0.02)\end{array}$ \\
\hline Constant & $\begin{array}{c}0.77 \\
(0.10)\end{array}$ & $\begin{array}{c}0.75 \\
(0.10)\end{array}$ & $\begin{array}{c}0.76 \\
(0.10)\end{array}$ & $\begin{array}{l}0.97 \\
(0.11)\end{array}$ & $\begin{array}{c}0.58 \\
(0.06)\end{array}$ & $\begin{array}{c}0.58 \\
(0.06)\end{array}$ & $\begin{array}{c}0.58 \\
(0.06)\end{array}$ & $\begin{array}{c}0.77 \\
(0.05)\end{array}$ \\
\hline Wave FE & $\sqrt{ }$ & $\sqrt{ }$ & $\sqrt{ }$ & $\sqrt{ }$ & $\sqrt{ }$ & $\sqrt{ }$ & $\sqrt{ }$ & $\sqrt{ }$ \\
\hline Municipality FE & $\checkmark$ & $\checkmark$ & $\sqrt{ }$ & $\sqrt{ }$ & $\checkmark$ & $\checkmark$ & $\checkmark$ & $\sqrt{ }$ \\
\hline Socio-economic controls & $\checkmark$ & $\checkmark$ & $\sqrt{ }$ & $\checkmark$ & $\checkmark$ & $\checkmark$ & $\checkmark$ & $\checkmark$ \\
\hline Political controls & $\checkmark$ & $\checkmark$ & $\checkmark$ & $\checkmark$ & $\checkmark$ & $\sqrt{ }$ & $\checkmark$ & $\checkmark$ \\
\hline$\overline{\mathrm{O}} \overline{\mathrm{bs}}------$ & $4 \overline{0} \overline{0}$ & 4070 & $4070^{-}$ & 4018 & $4 \overline{15} \overline{6}$ & $4 \overline{15} \overline{6}$ & $\overline{4156}$ & $\overline{4018}$ \\
\hline Municipalities & 856 & 856 & 856 & 855 & 873 & 873 & 873 & 855 \\
\hline $\operatorname{adj} . R^{2}$ & 0.31 & 0.31 & 0.31 & 0.34 & 0.13 & 0.13 & 0.13 & 0.20 \\
\hline $\operatorname{adj} . R^{2}$ (within) & 0.15 & 0.15 & 0.15 & 0.18 & 0.02 & 0.02 & 0.02 & 0.11 \\
\hline RMSE & 0.41 & 0.42 & 0.42 & 0.41 & 0.29 & 0.29 & 0.29 & 0.26 \\
\hline
\end{tabular}




\section{A.6.3 Mobilization of inactive voters}

We have re-run our entire analysis on both the regional- and individual-level with regard to participation in the referendum rather than regarding its outcome. Much in contrast to the robust impact on the No-vote share, the effects of M5S exposure on turnout are somewhat inconclusive and do not allow for a clear-cut interpretation of the underlying mobilization story. The results of the regional analysis appear model-dependent and difficult to interpret jointly, Figure A.10.

Figure A.10: Effect of M5S events on 'Yes' and turnout on municipality level

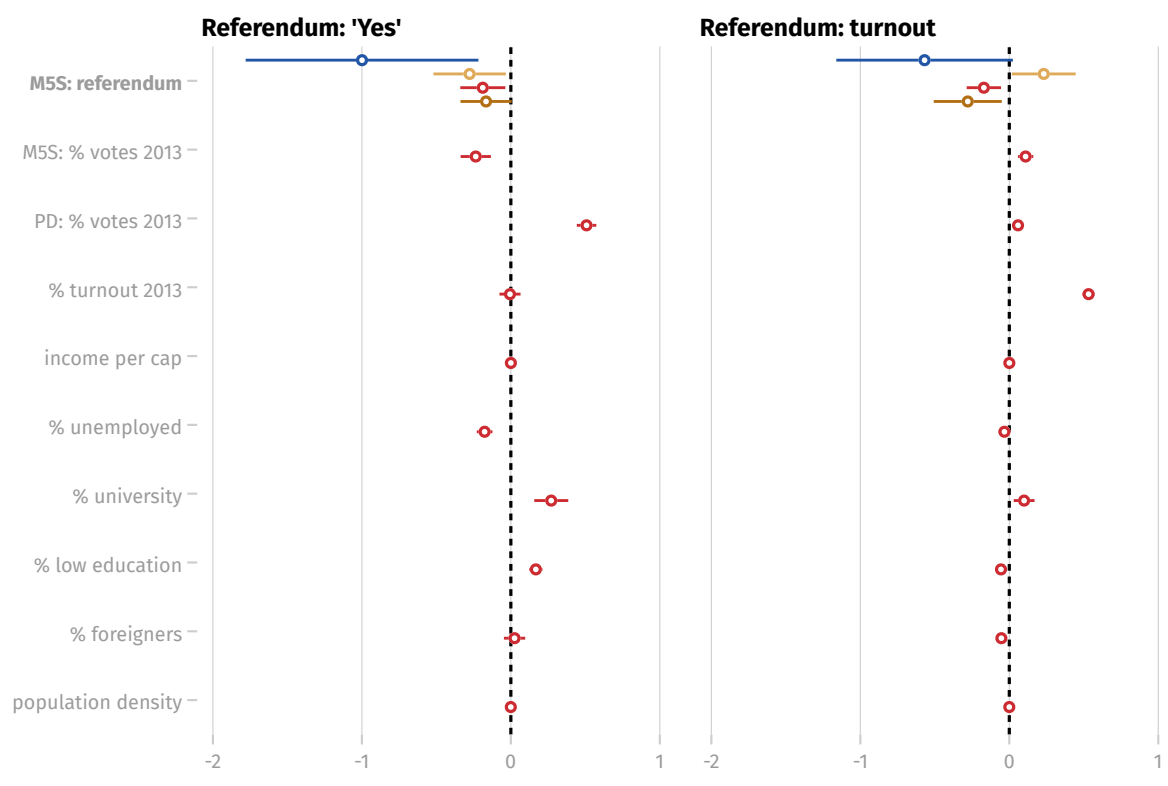

The individual-level analysis suggests a weak positive effect on turnout, Figure A.11.

As there remains some empirical ambiguity, we would not feel confident to interpret the findings as clear evidence in favor of either channel. The additional evidence most likely suggests a combination of successful mobilization of already activated in-partisans and, to a lesser extent, successful irritation of initial proponents of the referendum.

\section{A.7 Indoor vs. outdoor events}

In the main body of the text we compare the differential effects of indoor and outdoor events. The idea behind this analyses that indoor events tend to be organized for supporters. Even if new supporters might join these events, their effect should be limited to well-informed insiders. It is unlikely that what we call bystanders citizens who fairly randomly notice the event, get affected by it - join such events which are held behind closed doors.

In contrast, outdoor events are very likely to attract and affect bystanders. Since these events are held in public, visible to everyone, they are much more likely to mobilize votes against the reform among the wider public.

Of course the strong assumption we have to make is that in general these events are not drastically different in their key characteristics - such as the amount of people rsvping for these events. Our prior was 
Figure A.11: Effect of M5S events on individual voting on 'Yes' and turnout in referendum

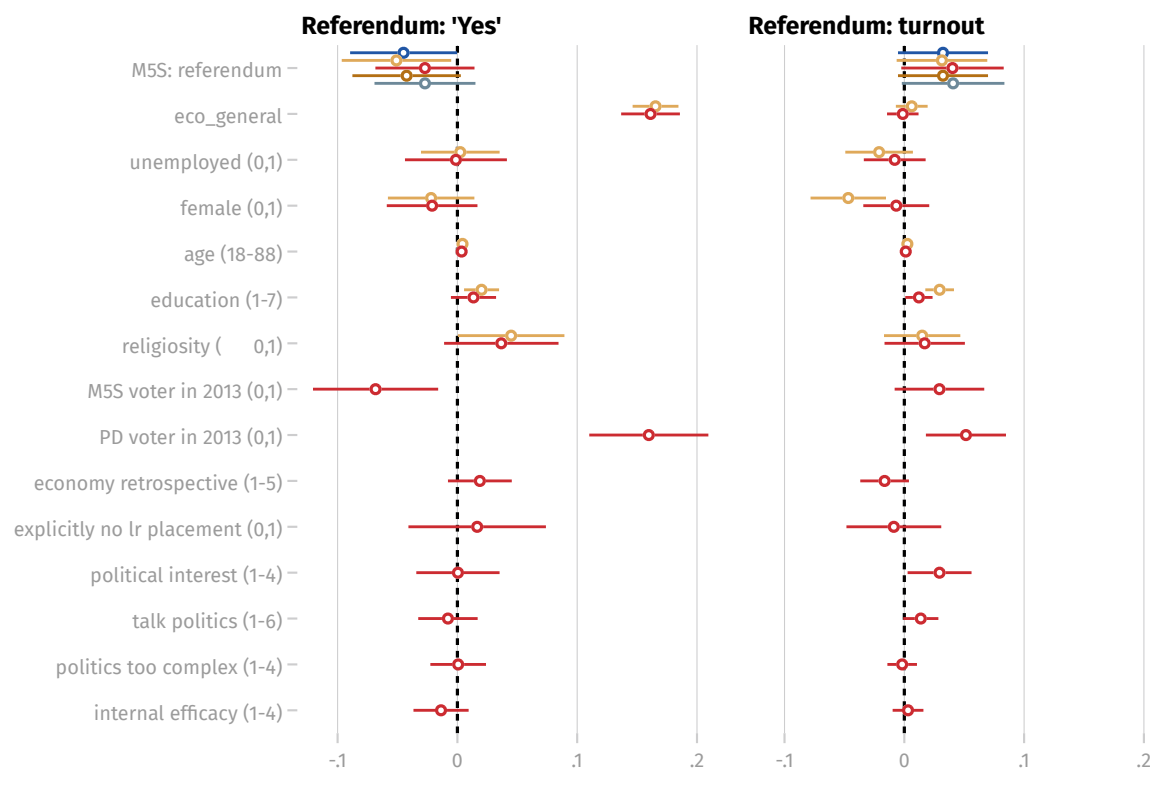

that outdoor events also have much more rsvps; however, this is not the case. As can be seen in Figure A.12 we find the exact opposite. On the mean, 24 more people rsvp for indoor than for outdoor events. A similar pattern emerges for the number of events organized reported in Figure A.13. This further underpins the fact,

Figure A.12: RSVPs for indoor and outdoor events

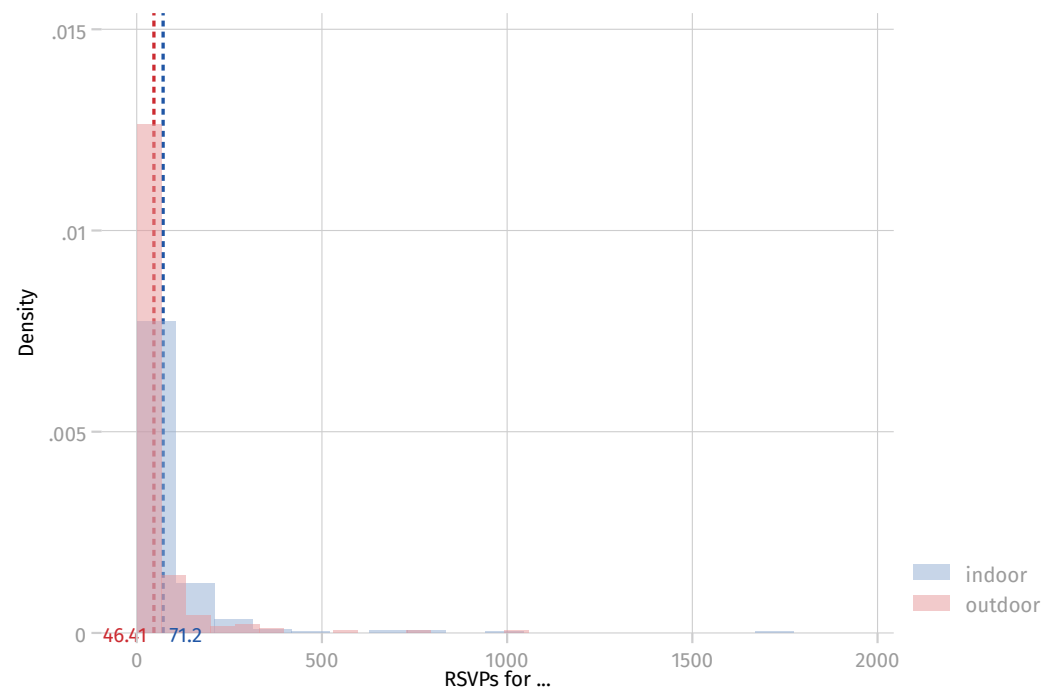

that outdoor events are likely to mobilize bystanders. Otherwise their effect should not be larger event though less people sign up for these events.

Below we then report the results of Figure 6 . In the upper part of Figure 6 we seek to understand if outdoor or indoor events have a stronger effect on the No Votes. We use the same models as in the main body of the text for regional- and individual-level but instead of using an overall measure for M5S mobilization we split 
Figure A.13: Number of events indoor and outdoor

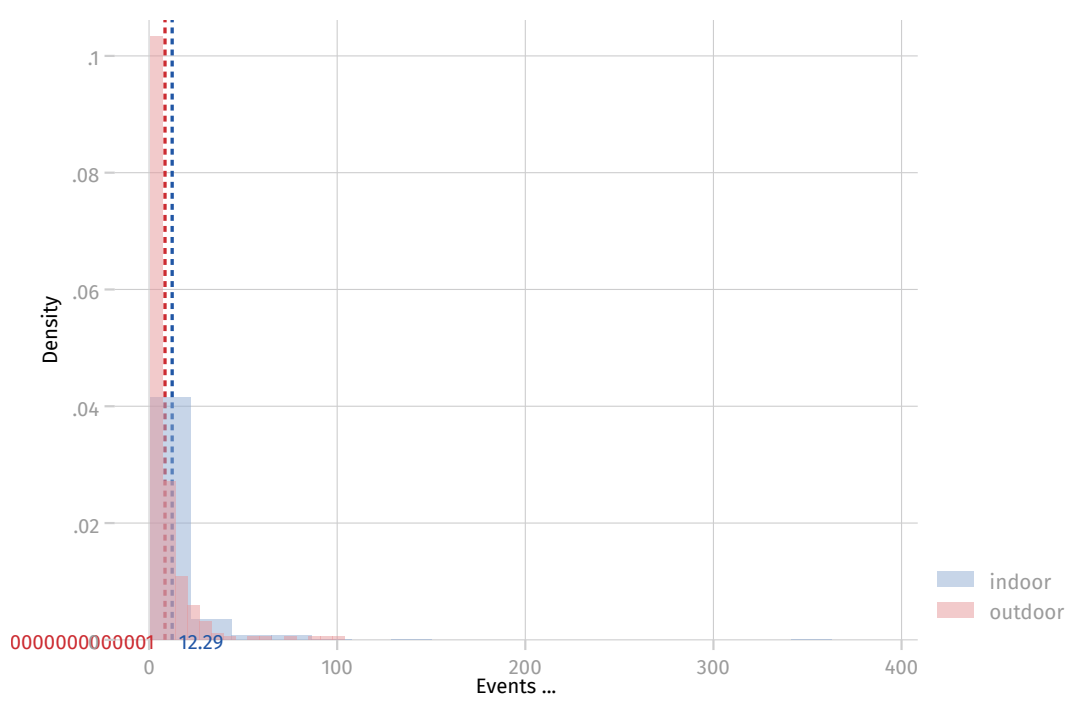

the events into indoor and outdoor events as outlined above:

Table A.11: OLS estimates (regional and individual), Are there differences in the effects of indoor vs. outdoor events? Yes.

\begin{tabular}{|c|c|c|c|c|c|c|}
\hline & \multicolumn{3}{|c|}{ regional } & \multicolumn{3}{|c|}{ individual } \\
\hline & $\begin{array}{c}(1) \\
\text { vote no }(0-100)\end{array}$ & $\begin{array}{c}(2) \\
\text { vote no }(0-100)\end{array}$ & $\begin{array}{c}(3) \\
\text { vote no }(0-100)\end{array}$ & $\begin{array}{c}(4) \\
\text { vote no }(0,1)\end{array}$ & $\begin{array}{l}(5) \\
\text { vote no }(0,1)\end{array}$ & $\begin{array}{c}(6) \\
\text { vote no }(0,1)\end{array}$ \\
\hline M5S indoor & $\begin{array}{c}0.23 \\
(0.14)\end{array}$ & & $\begin{array}{l}-0.07 \\
(0.17)\end{array}$ & $\begin{array}{c}0.02 \\
(0.03)\end{array}$ & & $\begin{array}{c}0.01 \\
(0.03)\end{array}$ \\
\hline M5S outdoor & & $\begin{array}{c}0.59 \\
(0.19)\end{array}$ & $\begin{array}{c}0.65 \\
(0.21)\end{array}$ & & $\begin{array}{c}0.08 \\
(0.03)\end{array}$ & $\begin{array}{c}0.08 \\
(0.03)\end{array}$ \\
\hline Wave FE & & & & $\sqrt{ }$ & $\sqrt{ }$ & $\checkmark$ \\
\hline Province FE & $\checkmark$ & $\checkmark$ & $\checkmark$ & & & \\
\hline Municipality FE & & & & $\checkmark$ & $\checkmark$ & $\checkmark$ \\
\hline$\overline{\mathrm{O}}_{\mathrm{bs}}-\dot{-}--$ & $\overline{7804}$ & $780 \overline{-}$ & $784^{-}$ & $\overline{5} 1 \overline{6} 6$ & $\overline{516} \overline{6}$ & $516 \overline{6}$ \\
\hline Municipalities & & & & 1012 & 1012 & 1012 \\
\hline $\operatorname{adj} . R^{2}$ & 0.71 & 0.71 & 0.71 & 0.51 & 0.51 & 0.51 \\
\hline adj. $R^{2}$ (within) & 0.34 & 0.34 & 0.34 & -0.00 & 0.00 & 0.00 \\
\hline RMSE & 4.69 & 4.69 & 4.69 & 0.35 & 0.35 & 0.35 \\
\hline
\end{tabular}

Note: Clustered standard errors by by province (regional) and individual $\times$ municipality

(individual) in parentheses. All controls omitted from table but same as in the main body

of the text reported in Table 1 and Table 2.

\section{A.8 Summary statistics}


Table A.12: Summary statistics for regional-level cross-sectional data data

\begin{tabular}{lccccc}
\hline \hline & Mean & SD & Min & Max & $\mathrm{N}$ \\
\hline \% No in referendum & 59.52 & 8.75 & 14.84 & 88.24 & 7,994 \\
M5S activity (o,1) & 0.08 & 0.27 & 0.00 & 1.00 & 7,998 \\
M5S activity (cont.) & 0.18 & 0.68 & 0.00 & 6.51 & 7,994 \\
M5S: \% votes 2013 & 18.42 & 5.91 & 0.13 & 49.87 & 7,939 \\
PD: \% votes 2013 & 18.59 & 6.59 & 0.88 & 53.48 & 7,939 \\
\% turnout 2013 & 74.60 & 7.85 & 20.34 & 100.00 & 7,939 \\
income per cap & $12,024.69$ & $3,049.70$ & $3,111.28$ & $29,210.04$ & 7,998 \\
\% unemployed & 10.26 & 6.32 & 0.64 & 42.18 & 7,913 \\
\% university degree & 7.08 & 2.58 & 0.57 & 27.02 & 7,939 \\
\% low education & 33.28 & 7.60 & 9.01 & 85.84 & 7,832 \\
\% foreigners & 6.60 & 4.46 & 0.00 & 33.75 & 7,965 \\
population density 2016 & 303.30 & 652.78 & 0.75 & $12,972.39$ & 7,998 \\
M5S activity (cont.) & 0.11 & 0.45 & 0.00 & 4.96 & 7,994 \\
M5S: adjacent, referendum & 1.38 & 2.16 & 0.00 & 9.97 & 7,994 \\
distance to closest UGS (in km) & 14.10 & 8.94 & 0.00 & 212.02 & 7,938 \\
days since formation & 132.88 & 522.98 & 0.00 & $4,148.00$ & 7,998 \\
M5S post referendum & 0.19 & 0.73 & 0.00 & 5.76 & 7,994 \\
M5S indoor & 0.05 & 0.31 & 0.00 & 4.46 & 7,994 \\
M5S outdoor & 0.04 & 0.23 & 0.00 & 3.77 & 7,994 \\
\hline \hline
\end{tabular}

Table A.13: Summary statistics for ITANES panel data

\begin{tabular}{lccccc}
\hline \hline & Mean & SD & Min & Max & $\mathrm{N}$ \\
\hline vote no (0,1) & 0.45 & 0.50 & 0.00 & 1.00 & 5,966 \\
M5S: referendum & 0.86 & 1.00 & 0.00 & 5.01 & 5,282 \\
economic evaluation (1-5) & 2.63 & 0.89 & 1.00 & 5.00 & 5,901 \\
unemployed (0,1) & 0.43 & 0.49 & 0.00 & 1.00 & 5,901 \\
female (0,1) & 0.48 & 0.50 & 0.00 & 1.00 & 5,966 \\
age (18-88) & 48.13 & 17.10 & 18.00 & 88.00 & 5,922 \\
education (1-7) & 5.01 & 1.41 & 1.00 & 7.00 & 5,922 \\
religiosity (0,1) & 0.83 & 0.38 & 0.00 & 1.00 & 5,966 \\
M5S voter in 2013 (0,1) & 0.22 & 0.42 & 0.00 & 1.00 & 4,232 \\
PD voter in 2013 (0,1) & 0.27 & 0.45 & 0.00 & 1.00 & 4,232 \\
economy retrospective (1-5) & 1.84 & 0.85 & 1.00 & 5.00 & 5,301 \\
explicitly no Ir placement (0,1) & 0.17 & 0.38 & 0.00 & 1.00 & 5,336 \\
political interest (1-4) & 3.02 & 0.77 & 1.00 & 4.00 & 5,265 \\
talk politics (1-6) & 4.51 & 1.54 & 1.00 & 6.00 & 5,223 \\
economy retrospective (1-5) & 1.84 & 0.85 & 1.00 & 5.00 & 5,301 \\
explicitly no Ir placement (0,1) & 0.17 & 0.38 & 0.00 & 1.00 & 5,336 \\
politics too complex (1-4) & 2.34 & 0.99 & 1.00 & 4.00 & 5,218 \\
internal efficacy (1-4) & 2.08 & 0.98 & 1.00 & 4.00 & 5,212 \\
\hline \hline
\end{tabular}




\section{References: Supporting Information}

Campante, Filipe, Ruben Durante, and Francesco Sobbrio. 2018. "Politics 2.0: The Multifaceted Effect of Broadband Internet on Political Participation." Journal of the European Economic Association 16 (4): 1094-1136.

Kearney, Melissa S., and Phillip B Levine. 2015. “Media influences on social outcomes: The impact of MTV's 16 and pregnant on teen childbearing." American Economic Review 105 (12): 3597-3632.

Schaub, Max, and Davide Morisi. 2020. "Voter Mobilisation in the Echo Chamber: Broadband Internet and the Rise of Populism in Europe." European Journal of Political Research p. (forthcoming). 